\title{
X-ray Standing Waves and Molecular Dynamics Studies of Ion Surface Interactions in Water at a Charged Silica Interface
}

\author{
Florent Malloggi, ${ }^{\dagger}$ Soumaya ben Jabrallah, ${ }^{\dagger}$ Luc Girard, ${ }^{\ddagger}$ Bertrand Siboulet, ${ }^{\ddagger}$ \\ Kunyu Wang, ${ }^{\ddagger}$ Philippe Fontaine, ${ }^{\top}$ and Jean Daillant*, \\ $\dagger L I O N S$, NIMBE, CEA, CNRS, Université Paris-Saclay, CEA Saclay 91191 Gif sur \\ Yvette Cedex, France \\ $\ddagger$ ICSM, CEA,CNRS,ENSCM, Univ.Montpellier, Marcoule, F-30207 Bagnols-sur-Cèze, \\ France \\ ๑ Synchrotron SOLEIL, L'Orme des Merisiers, Saint-Aubin, BP 48, \\ F-91192 Gif-sur-Yvette Cedex, France \\ E-mail: florent.malloggi@cea.fr;jean.daillant@synchrotron-soleil.fr
}

\section{Abstract}

The adsorption of monovalent ions in millimolar concentrations at the silica - solution interface has been investigated using $\mathrm{x}$-ray standing waves, a method which combines element sensitivity and sub-nanometer depth resolution. Results were analyzed using a model free analysis and a Gouy-Chapman-Stern model giving access to interfacial concentration profiles. We find the concentration of Potassium cations in the Stern layer to be slighly higher than that of Cesium cations. They also come closer to the interface, in agreement with our molecular dynamics simulations which suggest that our experimental results can be explained by the higher ability of smaller cations to share their hydration shell with the surface. Extension of the method to different systems can provide the necessary experimental basis to benchmark ionsurface potentials, a necessary step to predict interfacial behavior of ions which is of high relevance to several areas of science and technology.

\section{Introduction}

A precise understanding of the distribution of chemical species at interfaces becomes increasingly important as it is realized that a finer control of interfacial chemical processes is crucial to solve the grand challenges facing energy research, advanced materials synthesis or the environment. Solid electrode - electrolyte interfaces play for example a crucial role in battery research ${ }^{1}$ and similar considerations apply more generally to energy storage systems and catalysis. In environmental sciences, the interaction between ions, humics and minerals influences the mobility and availability of pollutants, ${ }^{2}$ but halide ion distribution in sea salt aerosols is also expected to play a critical role in atmospheric tropospheric ozone destruction. ${ }^{3}$

Historically, ions at interfaces have been associated with colloidal science as the modulation of the effective surface charge by ion-surface interactions affects the structure of the electric double layer, hence the interaction between charged particles in aqueous solutions ${ }^{4}$ as described by the Gouy-Chapman-Stern model which combines a description of the Stern layer with different possible degrees of sophistication 
with Poisson-Boltzmann statistics for the diffuse layer (Fig. 1 top and Sect. "Analysis of the standing wave curves"). ${ }^{4,5}$

The composition and structure of the Stern layer usually exhibits pronounced specifity, referring to phenomena where ions of the same valency have a different effect which have been the subject of extensive work and reviews. ${ }^{6-9}$ These effects resulting from a subtle balance between polarisabilty, hydration and interfacial water structure usually follow "Hofmeister series" $\left(\mathrm{SCN}^{-}>\mathrm{ClO}_{4}^{-} \approx \mathrm{I}^{-}>\mathrm{Br}^{-}>\mathrm{Cl}^{-}>\mathrm{F}^{-}\right.$ for anions) in direct or reverse order. $8,10,11$

Titration of colloidal suspensions. Experimentally, the effect of different cations on surface charge was first investigated using potentiometric titration of colloidal suspensions in aqueous electrolyte solutions of various ionic strengths to determine charge vs $\mathrm{pH}$ curves which were analyzed using increasingly sophisticated models. ${ }^{4,5,12-16}$ Surface equilibria were determined using radioactive tracers. ${ }^{17}$

Noting that surface chemistry depends on which type of silica is considered and that geometry also matters (nanoparticles or planar surfaces), the point of zero charge (p.z.c.) of silica surfaces mainly fixed by the dissociation of silanol groups is usually found in the range 2-2.5. ${ }^{4}$ Using deuterium exchange with mass spectrometric analysis, Zhuravlev ${ }^{18}$ found a silanol site density of fully hydroxylated surfaces to be fairly independent on the type of silica $\approx 4.9 \pm 1 \mathrm{OH} / \mathrm{nm}^{2}$. However, the site density of nonporous, fully hydrated colloidal silica prepared by polymerization in solution, is believed to be on the order of 8 sites $/ \mathrm{nm}^{2} .{ }^{19}$

Substantial charging only starts several $\mathrm{pH}$ units above the p.z.c. ${ }^{12}$ Surface charges do not exceed $0.1 \mathrm{C} / \mathrm{m}^{2}$ at $\mathrm{pH}$ values below $7,{ }^{12,14}$ whereas it can reach $-1 \mathrm{C} / \mathrm{cm}^{2}$ or more in $0.1 \mathrm{M}$ $\mathrm{CsCl}$ at $\mathrm{pH} 10$ suggesting penetration of coand counter-ions in a surface gel layer. ${ }^{12}$

Regarding cation specificity, Lyklema ${ }^{12}$ showed that the (negative) charge of 50-100 nm B.D.H. silica particles at $\mathrm{pH}$ above 7 increases in the order $\mathrm{Li}^{+}<\mathrm{Na}^{+}<\mathrm{K}^{+}<\mathrm{Cs}^{+}$, whereas the reversed trend was possibly observed for
$3<\mathrm{pH}<6$. They interpreted the high $\mathrm{pH}$ behavior as due to the easier penetration of smaller cations into the pores of the surface gel layer at high $\mathrm{pH}$ where they partly compensate for $\mathrm{OH}^{-}$adsorption, though the possibility of regular specific adsorption was not completely ruled out. Using $\mathrm{Na}^{22}$ as a tracer, Tien ${ }^{17}$ found selectivity coefficients ranking in the order $\mathrm{Li}^{+}$ $<\mathrm{Na}^{+}<\mathrm{K}^{+}<\mathrm{Cs}^{+}$for silica gel at $\mathrm{pH}=6.9$ and considered both cation exchange and physical sorption in its discussion of previous results. The same trend (i.e. association in the order $\mathrm{Li}^{+}<\mathrm{Na}^{+}<\mathrm{K}^{+}<\mathrm{Cs}^{+}$) was found in measurements performed with $4<\mathrm{pH}<8$ in Ref., ${ }^{14}$ in agreement with results obtained on porous silica. Analyzing these data using the Stern-Gouy-Chapman model gives association constants which increase from $\mathrm{Li}^{+}$to $\mathrm{Cs}^{+}$, with $\log \mathrm{K}_{K^{+}}=-0.5 /-1$ and $\log \mathrm{K}_{C s^{+}}=-0.1 / 0.2$ for $4 \mathrm{~nm}$ AEROSIL 300 silica particles. ${ }^{15}$ Note however that a very small site density $\approx 0.7$ $/ \mathrm{nm}^{2}$ was reported for those nanoparticles and the same data could be analyzed using a purely electrostatic model including an ion free Stern layer (i.e. no specific adsorption) taking into account the geometry of the $4 \mathrm{~nm}$ in radius spherical particles, yielding ionic radii in good agreement with literature values for hydrated cations. ${ }^{14}$ Kobayashi et al. also analyzed their Stöber silica particles in background $\mathrm{KCl}$ electrolyte without taking into account specific adsorption. ${ }^{20}$ For a similar system, ${ }^{21}$ Davis ${ }^{13}$ reports a $\log K_{K^{+}}=0.5$ with a surface site density of $5 / \mathrm{nm}^{2}$. Again using potentiometric titration data, Tao and Zhang ${ }^{22}$ find $\mathrm{pK}_{H^{+}}=$ - $\log \left(\mathrm{K}_{H^{+}}\right)=6.57$ and similar $\log \mathrm{K}$ values for $\mathrm{Li}^{+}, \mathrm{Na}^{+}$and $\mathrm{K}^{+}$on the order of 1 .

To summarize, for silica colloidal suspensions, adsorption is usually found to increase in the order $\mathrm{Li}^{+}<\mathrm{Na}^{+}<\mathrm{K}^{+}<\mathrm{Cs}^{+}$, with association constants on the order of -0.5 to 1 . The electrokinetic $\zeta$ potential can also be measured at planar surfaces in capillaries. The value of the electrokinetic potential for a planar surface at a given $\mathrm{pH}$ can be significantly different from that of nanoparticles. ${ }^{23}$

Surface force measurements. Another way to determine association constants is to 
measure interactions in a background electrolyte using the Surface Force Apparatus or an Atomic Force Microscope (AFM). ${ }^{24-29}$ Fitting of the force vs distance curve which depend on the interfacial layer composition and structure to a model then gives access to the strength of the interaction between ions and surfaces.

Determining association constants from surface force measurements between pyrogenic silica surfaces in $10^{-4} \mathrm{M}-10^{-1} \mathrm{M}$ electrolytes at $\mathrm{pH}$ $=5.5$, Chapel found $\mathrm{pK}_{H^{+}}$in the range 6.2-6.5 and a slightly stronger association for $\mathrm{K}^{+}$with $\log \mathrm{K}_{K^{+}}=3.2$ than for $\mathrm{Cs}^{+}$with $\log \mathrm{K}_{\mathrm{Cs}^{+}}=$ $2.97 .{ }^{26}$ A stronger effect of $\mathrm{Li}^{+}$on the short range hydration force was attributed to its "structure breaker" character in that context, being the most hydrated cation. These values are close to the values found by Pashley for the mica surface. ${ }^{24,25}$ Investigating the interaction between a silica colloid and a (100) silicon surface in a pH range of 4 to 10, Dishon et al. ${ }^{27}$ found an increased adsorption in the order $\mathrm{Li}^{+}<\mathrm{Na}^{+}<\mathrm{K}^{+}<\mathrm{Cs}^{+}$at $\mathrm{pH}=$ 5.5 and reversal occuring in between $\mathrm{pH} 6$ and 7. Extending the measurements to higher $\mathrm{pH}$ values, reversed ordering was found above $\mathrm{pH}$ $=7.5^{28}$ interpreted as due to the formation of a strong hydration layer leading to a stronger repulsion of the weakly hydrated $\mathrm{Cs}^{+}$cations. This is exactly opposite to the behavior found in Ref. ${ }^{12}$ for a different type of silica. Using an AFM and directly measuring the force between the tip and a silica surface in $1 \mathrm{mM}-100 \mathrm{mM}$ solutions, Zhao et al. ${ }^{29}$ find $\log K_{K^{+}}=2.0 \pm$ 0.2 , slightly larger than $\log \mathrm{K}_{\mathrm{Na}^{+}}=1.65 \pm 0.1$, whereas $\mathrm{pK}_{H^{+}}=6.9 \pm 0.3$.

All these measurements show a general agreement for $\mathrm{pK}_{H^{+}}$which is found in the range 6.5-7.5, and association constants determined using force measurements are consistenly larger than those obtained in titration experiments.

\section{Electric potential measurement using} photoemission. Following pioneering work at the electrolyte-air interface, ${ }^{30}$ photoemission has also been used to investigate the structure of the Stern layer with the distinctive feature that photoelectrons are directly sensitive to the local electric potential. ${ }^{31-33}$ In recent experi- ments, Brown et al. measured the potential drop across the double layer for silica nanoparticles using combined potentiometric titration and near ambient pressure photoemission in a liquid jet. ${ }^{31-33}$ For $50 \mathrm{mM}$ solutions and $\mathrm{pH}$ 10, they found potential drops across the double layer ranging from $-265 \mathrm{mV}$ for $\mathrm{CsCl}$ to -415 $\mathrm{mV}$ for $\mathrm{LiCl}$ showing marked specificity. Adsorption increases in the order $\mathrm{Li}^{+}<\mathrm{Na}^{+}<$ $\mathrm{K}^{+}<\mathrm{Cs}^{+}$unlike observed in ${ }^{28}$ above $\mathrm{pH}=7.5$. Using measurements of the $\zeta$ potential and the dependence of the capacitance on the capacitor thickness, they derive Stern layer thicknesses ranging from $4.6 \AA$ for $\mathrm{CsCl}$ to $8 \AA$ for $\mathrm{LiCl}$, which they rationalize according to the size of hydrated cations.

Theory. Turning now to theoretical predictions, different models have been proposed to predict equilibrium constants like the famous MUSIC (MUltiSIte Complexation) model, ${ }^{19,34}$ which explicitely takes into account local Coulombic interactions depending on the valence of the cation and its electron configuration, the type and number of surrounding ligands and cation-surface groups distance. A $\mathrm{pK}_{H}^{+}$value of 7.5 was readily calculated from the initial model ${ }^{34}$ allowing the analysis of earlier titration experiments by Bolt. ${ }^{35}$ The model was further extended to account for adsorbed surface complexes (CD-MUSIC). ${ }^{36}$

Another approach consists in estimating the different contributions (solvation, electrostatic) to the Gibbs free energy of surface protonation reactions using predictive equations involving parameters known independently like dielectric constant or Pauli bond strength and calibration of the model against experimentally determined equilibrium constants. ${ }^{37}$ A compilation of titration results for different surfaces and ions within the framework of this predictive extended triple layer model for surface charge can be found in Ref. ${ }^{37} \log K_{K^{+}}$values in the range $1.3-2$ and $\log K_{C s^{+}}$values in the range $2.0-2.4$ are reported, the largest values being for quartz and the lower ones for amorphous silica, with adsorption increasing from $\mathrm{Li}^{+}$to $\mathrm{Cs}^{+}$as previously reported.

More recently, progress has been made using 
both more powerful simulations ${ }^{10,38-40}$ and experimental methods.

Molecular simulations. Molecular simulations were also used to investigate the silica surface electrolyte interface. Schwierz et al. investigated the behavior of ions at both hydrophylic and hydrophobic interfaces and found a reversal of the Hofmeister series with $\mathrm{Li}^{+}$showing the strongest interaction with hydrophilic surfaces. ${ }^{39}$ In Refs., ${ }^{40,41} \mathrm{Li}^{+}, \mathrm{Na}^{+}$, $\mathrm{K}^{+}$and $\mathrm{Cs}^{+}$have been studied on surfaces comprising siloxane and silanol groups, possibly deprotonated to simulate the effect of pH. A simple model based on Grahame equation and complexation constants was used to estimate the outer Helmholtz plane potential $\phi\left(z_{\text {out }}\right)$ identified with the $\zeta$ potential. Complexation strongly increases from $\mathrm{Cs}^{+}$to $\mathrm{Li}^{+}$ as the association of ions of similar size (here the negatively charged oxygen in deprotonated silanol) is always favoured. ${ }^{9}$ Similarly Bouhadja and Skelton ${ }^{42}$ find a stronger adsorption of $\mathrm{Na}^{+}$ than $\mathrm{K}^{+}$and Dewan et al. a stronger adsorption of $\mathrm{Na}^{+}$compared to $\mathrm{Cs}^{+}$as $\mathrm{Cs}^{+}$retains its hydration shell. ${ }^{43}$ For an effective charge of -e on deprotonated silanols which is a parameter of her simulation, Hocine et al. find no association of $\mathrm{Cs}^{+} .{ }^{41}$ Their association constants are at most $\log K_{K^{+}}=1.65 \log K_{C^{+}}=0.91$ for an effective charge of -1.5 e on deprotonated silanols and they predict an inversion of selectivity around $\mathrm{pH}=7$ as adsorption on siloxanes is preferred for low $\mathrm{pH}$ values.

$X$-ray standing waves. In this work, we have used X-ray standing waves which have the advantage of combining depth and element sensitivity to determine ionic concentration profiles at the solid - solution interface. A standing wave field is created whenever an incident beam interferes with a reflected beam. ${ }^{44}$ For Bragg reflection from a periodic structure, crystal or artificial multilayer, the period of the standing wave field is the period of the structure used to create it. Recording the element specific fluorescence in the standing wave field therefore allows the determination of the distribution of this element with a resolution which is a frac- tion of the underlying substrate period. The technique has already been used to investigate the electrical double layer at a planar mirror ${ }^{45}$ and adsorption at crystal - solution interfaces. ${ }^{46}$ In a previous study, we used a multilayer substrate to optimize the depth resolution. Some results were presented in Ref. ${ }^{47}$ and analyzed using a very simple Stern layer model. We present here new results complementing them with both a model free analysis, an analysis using Gouy-Chapman-Stern model and numerical simulations which confirm and extent the previous study. The results are critically discussed and compared to recent results obtained using complementary techniques.

\section{Materials and Methods}

\section{X-ray standing waves}

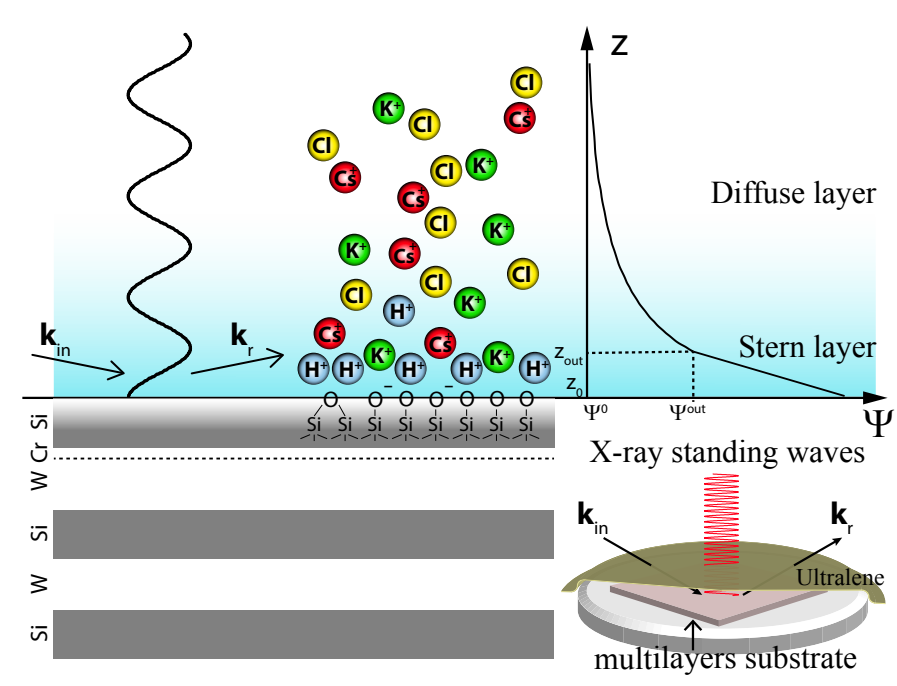

Figure 1: Schematics of the standing wave experiment. Incident (wave vector $\mathbf{k}_{\text {in }}$ ) and reflected (wave vector $\mathbf{k}_{\mathbf{r}}$ ) X-ray waves interfere to create a standing wave field perpendicular to the interface with period equal to that of the multilayer substrate. The species are excited in the standing waves field and emit fluorescence photons for absorption edges below the incident beam energy. Schematics of the experimental cell (bottom right). The liquid layer is confined between the multilayer (pink plate in figure) and a flexible X-ray transparent membrane (brown film in figure). 
Schematics of the standing wave experiment is presented in Fig. 1. Recording the fluorescence of a given atom while scanning the grazing angle of incidence across the Bragg peak yields a characteristic profile which allows the location of this atom (modulo the period of the underlying structure). More precisely,

$$
I(\theta)=B \int_{0}^{\infty} \rho(z) T(z)|E(z)|^{2} d z,
$$

where $\rho(z)$ is the concentration profile of the element of interest. The constant B depends on the fluorescence yield, detection efficiency and geometrical factors. $E(z)$ is the electric field which can be calculated using the classical matrix method. ${ }^{48} T(z)$ is the transmission coefficient for the fluorescence intensity between the emitting atom and the detector. The standing wave amplitude calculated for the experiments presented in this manuscript is displayed in Fig. 2 . The standing wave phase depends on the exact value of the grazing angle of incidence $\theta$ within the Bragg peak. It is shifted by $\pi$ when crossing the Bragg peak. More details about the calculation of the intensity can be found in Ref. ${ }^{47}$ For a crystal substrate, Angstrom resolution will be obtained, and using an artificial multilayer like in the present study, the period can be adjusted to the specific needs of the experiment. The method allows one to simultaneously investigate the positions of different atoms, monitoring their specific emission lines.

The experiments were performed at the SIRIUS beamline of synchrotron Soleil. We used a $7 \mathrm{keV}$ monochromatic beam $\left(\delta \mathrm{E} / \mathrm{E} \sim 10^{-4}\right) 7$ $\mathrm{keV} 3 \mathrm{~mm} \times 150 \mu \mathrm{m}(\mathrm{H} \times \mathrm{V})$ allowing one to resolve the Bragg peaks. The divergence of the probe beam is $0.05 \mathrm{mrad}$ for the horizontal direction and $0.1 \mathrm{mrad}$ for the vertical one. With this energy, the fluorescence of the $\mathrm{K}$ lines of chlorine and potassium as well as $\mathrm{L}$ lines of cesium and iodine could be recorded.

Fluorescence was measured using a Bruker Xflash QUAD 50404 element SDD fluorescence detector placed a few $\mathrm{mm}$ of the horizontally mounted sample and reflectivity was measured using a Hammamatsu diode mounted on the detector arm of the SIRIUS diffractometer. Ow-

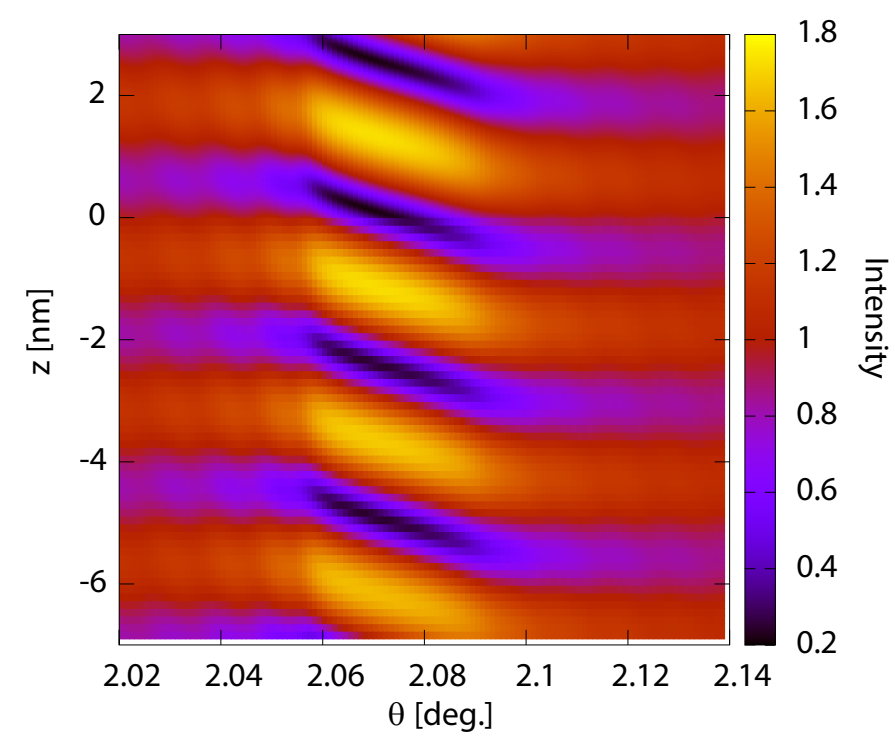

Figure 2: Amplitude of the standing wave field as a function of the grazing angle of incidence $\theta$ and distance $\mathrm{z}$ from the solid surface $($ at $\mathrm{z}=0$ ). Note that nodes become antinodes when crossing the Bragg peak centered at 2.073 degrees corresponding to a phase shift of $\pi$ of the standing wave field. The calculations were performed for the substrates used in these experiments (a multilayer composed of $1502.58 \mathrm{~nm}$ thick Si-W periods). 
ing to top-up injection of the storage ring, the stored intensity is kept constant and the sample is exposed to a constant intensity measured by a monitor, which is used for normalization.

\section{Experimental system}

The samples consisted in an ultra thin liquid layer sandwiched between the multilayer substrate used to create the standing waves and a $4 \mu \mathrm{m}$ thick Ultralene ${ }^{\circledR}$ X-ray transparent window. The substrates used in these experiments were $\mathrm{Si}-\mathrm{W} 1 \mathrm{~cm} \times 1 \mathrm{~cm}$ multilayers (150 periods of $2.58 \mathrm{~nm}$ as measured by reflectivity) manufactured by AXO (Dresden, Germany). They include a thin $(<0.5 \mathrm{~nm})$ Cr layer below the top silicon layer to serve as a reference for the phase. Exposure to air results in an oxydation of top silicon layer with silanol Si-OH groups being exposed at the surface. $^{49}$ Substrates were cleaned following the RCA cleaning procedure ${ }^{50}$ before being used. $\mathrm{KCl}$, CsCl, CsI (Sigma-Aldrich, 99.9995\% purity) and KI (Sigma-Aldrich, 99.999\% purity) were used without further purification. Molar stock solutions were prepared using water from a Millipore Milli-Q ${ }^{\circledR}$ system (18.2 M $\Omega . c m$ resistivity) and further diluted and mixed just before the experiments. Small volumes of solution ranging from $750 \mathrm{nl}$ to $4 \mu \mathrm{l}$ were introduced in the cell. The multilayer was then pressed against the cover Ultralene ${ }^{\circledR}$ film allowing for the control of the sample thickness (Fig. 1 bottom right). We carefully checked that this does not lead to any deformation of the $1 \mathrm{~mm}$ thick substrate which would lead to a broadening of the reflected beam compared to the incident beam which we do not observe. Moreover, reflectivity measurements provide an accurate determination of the surface roughness which is as low as $2 \AA$ and therefore does not affect the profile determination. Unless otherwise specified, experiments were conducted at ambient pH of 5.5 fixed by the carbon dioxide dissolved in water. All manipulations were performed in a clean room to avoid dust contamination.

The liquid film thickness was measured in-situ using $\mathrm{x}$-ray reflectivity. As the refractive index for $\mathrm{x}$-rays is $\mathrm{n}=1-\delta$ - $\mathrm{i} \beta$, with $\delta \approx 10^{-6}$ in the $5-10 \mathrm{keV}$ range, total external reflection occurs for grazing angles of incidence lower than the so-called critical angle for total external reflection $\theta_{c}=\sqrt{2 \delta} \approx 10^{-3} \mathrm{rad}$. For thicknesses $\approx$ $100 \mathrm{~nm}$, the measurement is mostly sensitive in the angular domain where $\mathrm{x}$-rays are still totally reflected from the substrate, but penetrate in the solution. Indeed the beam path in the sample is $L=2 t / \sin \theta$, with $t$ the thickness and $\theta$ the grazing angle of incidence, and attenuation varies as $\exp -L / L_{a t t}$, with $L_{a t t}$ the attenuation length in water at $7 \mathrm{keV} \approx 660 \mu \mathrm{m}$. For a grazing angle of incidence of 0.4 degrees, this leads to an attenuation ranging from a few $\%$ for a $100 \mathrm{~nm}$ thick film to $35 \%$ for a $1 \mu \mathrm{m}$ thick film. Examples are given in Fig. 3.

Due to the pressure exerted by the Ultralene ${ }^{\circledR}$ membrane, liquid films continue to thin out during the experiments. Their thickness was therefore measured before and after standing wave experiments and sometimes in between fluorescence measurements. In addition, all samples were carefully examined after the experiments, and the samples for which it could be suspected that they could have dried out were not further considered for analysis.

To take into account possible thinning of the liquid films, short measurements of the fluorescence curves $\approx 10 \mathrm{~min}$ for 50 points across the Bragg peak were repeated several times to increase statistics. In most cases, a single measurement was enough to get reasonable statistics, except for chlorine $K_{\alpha}(2622 \mathrm{eV})$ which has the lowest fluorescence energy and is therefore less efficiently excited by the $7 \mathrm{keV}$ incident radiation and more strongly absorbed than the other fluorescence lines. It is important to note that although there might be an electrical double layer at the Ultralene ${ }^{\mathrm{R}}$ interface, its contribution is blurred and does affect the fluorescence signal. Indeed for making a significant contribution to the fluorescence curves, the interface must be atomically flat and parallel to the substrate which is impossible with the flexible membrane we used. 


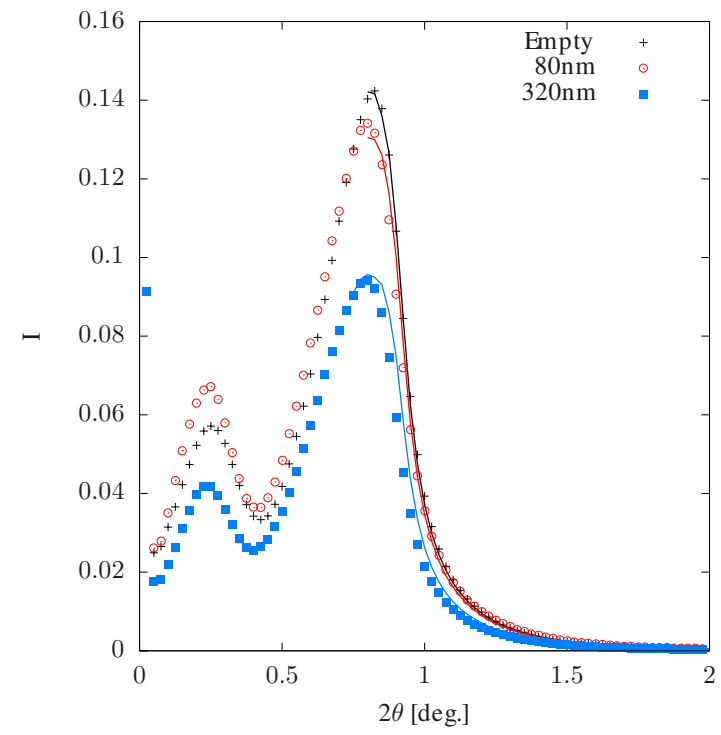

Figure 3: Reflectivity of an empty cell (black crosses), a cell filled with a $80 \mathrm{~nm}$ thick solution (red circles) and a $320 \mathrm{~nm}$ thick solution (blue squares) at grazing angles of incidence. Below $\approx 0.3^{\circ}$, X-rays are totally reflected from the Ultralene ${ }^{\mathrm{B}}$ cover film. In between $\approx 0.3^{\circ}$ and $\approx 1^{\circ} \mathrm{x}$-rays penetrate in the solution film but are still totally reflected from the substrate.

\section{Data analysis}

Our measurements provide a set of fluorescence spectra as a function of the grazing angle of incidence across the Bragg peak. The first step in the analysis is normalization and background subtraction. Background subtraction is important to remove parasitic fluorescence from the substrate or Ultralene ${ }^{\circledR}$ film (in particular sulfur, chlorine, argon, calcium) which could perturb the analysis. For this, we subtract the spectrum of an empty cell to the measured spectrum (Fig. 4) after applying a correction as absorption of the fluorescence radiation in the solution and the Ultralene ${ }^{\circledR}$ film is different for each energy, and this effect can be large at low energy (below $3 \mathrm{keV}$ ), even for small thicknesses. For this, we have modeled the attenuation length energy dependence with a fourth degree polynomial and applied an exponential correction to the measured data.

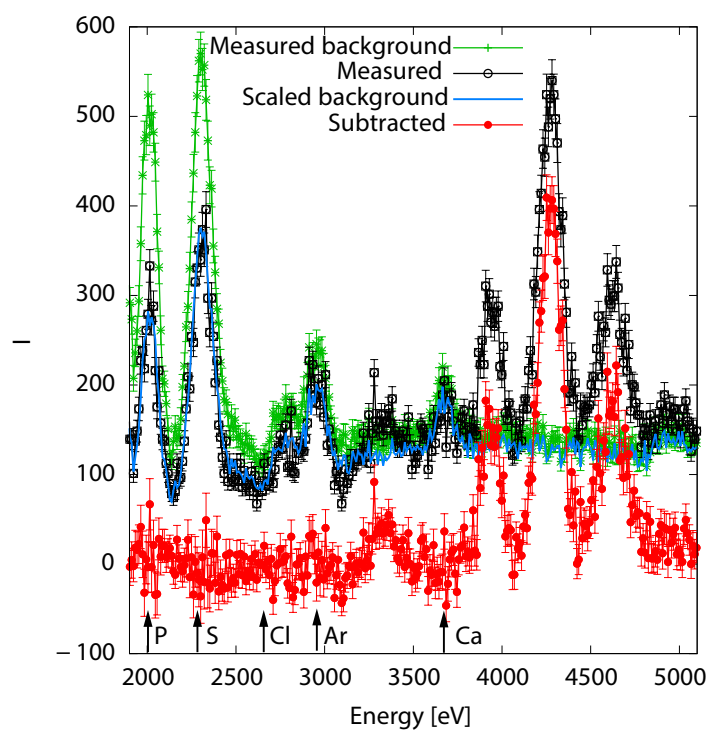

Figure 4: Background subtraction. An empty cell spectrum is subtracted to the measurement fluorescence intensity after correction for differential absorption at different energies. Note the excellent subtraction of phoshorus $\mathrm{K}_{\alpha}$ line (2014 eV), sulfur $K_{\alpha}(2308 \mathrm{eV})$, chlorine $\mathrm{K}_{\alpha}$ $(2622 \mathrm{eV})$, argon $\mathrm{K}_{\alpha}(2957 \mathrm{eV})$ and calcium $\mathrm{K}_{\alpha}$ $(3691 \mathrm{eV})$.

After background subtraction, the fluorescence curves were analyzed following the procedure detailed in Ref. ${ }^{51}$ using a home made soft- 
ware with a peak model based on the physics of detection, including a Voigtian peak shape, a tail and a shelf. ${ }^{52}$ The different peak parameters have a simple energy dependence, thus reducing the number of fitting parameters. Another advantage of this method is that the background from photon counting being built up by the shelf contributions, it is automatically and consistently subtracted.

This procedure yields a fluorescence curve as a function of the grazing angle of incidence across the Bragg peak for each element. These curves are then analyzed using Eq.(1). For that, Eq.(1) is discretized and the sample is divided in very thin slices $(0.5 \AA$ thick) where the ionic concentration can be considered to be constant and for which $\mathrm{E}(\mathrm{z})$ and $\mathrm{T}(\mathrm{z})$ can be calculated using the usual matrix method. ${ }^{47}$ The calculated curves are then fitted to the experimental curves using a standard least square procedure.

\section{Analysis of the Standing Wave Curves}

\section{Gouy-Chapman-Stern model}

A simple, yet including essential parameters model used to calculate the distribution of ions at interfaces is the double layer GouyChapman-Stern model where a single Stern layer ending at the "outer" Helmholtz plane located at $\mathrm{z}_{\text {out }}$ (Fig. 1) and a diffuse layer are considered. ${ }^{4,5}$ In the implementation used in this study, specific interactions of cations with a silica surface are taken into account via an association constant, and the Stern layer is simply described using its capacitance. The electric potential $\phi$ in the diffuse layer obeys the Poisson equation:

$$
\frac{d^{2} \phi}{d z^{2}}=-\frac{\rho}{\epsilon_{0} \epsilon_{r}}
$$

In Eq. (2), $\rho=\sum_{i} n_{i} e z_{i}$ is the charge density, with $n_{i}$ the concentration of the ion $i$ of valency $\mathrm{z}_{i}, e=1.602 \times 10^{-19} \mathrm{C}$ is the elementary charge, $\epsilon_{0}=8.85 \times 10^{-12} \mathrm{~F} / \mathrm{m}$ is the vacuum permittivity and $\epsilon_{r}$ the relative permittivity. Concen- trations in the diffuse layer obey a Boltzmann distribution:

$$
n_{i}=n_{i \infty} \exp \left(-\frac{z_{i} e \phi}{k_{B} T}\right),
$$

with $n_{i \infty}$ the bulk concentration, $k_{B}$ the Boltzmann constant and $T$ the temperature. Note that following traditionnal notations, $z$ is a distance whereas $z_{i}$ with a subscript is a valency. Insertion of Eq.(3) into Eq.(2) gives after simple integration the Poisson-Boltzmann equation for the potential:

$$
\left(\frac{d \phi}{d z}\right)^{2}=\frac{2 k_{B} T}{\epsilon_{0} \epsilon_{r}} \sum_{i} n_{i \infty}\left[\exp \left(-\frac{z_{i} e \phi}{k_{B} T}\right)-1\right]
$$

The charge in the diffuse layer can be written:

$$
\begin{aligned}
\sigma_{D L} & =\int_{z_{\mathrm{out}}}^{\infty} \rho(z) d z \\
& =-\int_{z_{\mathrm{out}}}^{\infty} \epsilon_{0} \epsilon_{r} \frac{d^{2} \phi}{d z^{2}} \\
& =-\left.\epsilon_{0} \epsilon_{r} \frac{d \phi}{d z}\right|_{z_{\mathrm{out}}} ^{\infty},
\end{aligned}
$$

where $z_{\text {out }}$ is the location of the "outer Helmholtz plane" which fixes the border between the Stern layer and the diffuse layer.

By inserting Eq. (4) in Eq. (5), one obtains

$$
\begin{aligned}
\sigma_{D L}^{2} & =2 k_{B} T \epsilon_{0} \epsilon_{r} \\
& \sum_{i} n_{i \infty}\left[\exp \left(-\frac{z_{i} e \phi\left(z_{\text {out }}\right)}{k_{B} T}\right)-1\right],
\end{aligned}
$$

known as the Grahame equation, which relates the charge in the electric double layer $\sigma_{D L}^{2}$ to the potential at the outer Helmholtz plane $\phi\left(z_{\text {out }}\right)$.

The composition of the Stern layer is determined by surface equilibria, related to the dissociation of surface silanol groups and association of cations on silanol or siloxane groups for our silica surface. For protons and a monovalent salt with cation $C_{i}^{+}$, one would have silanol 
dissociation:

$$
\begin{aligned}
\Gamma_{S i O^{-}}\left[H^{+}\right]_{z=0} & =\Gamma_{S i O^{-}}\left[H^{+}\right] e^{-\frac{e \phi(0)}{k_{B} T}} \\
& =K_{H} \Gamma_{S i O H}
\end{aligned}
$$

where $K_{H}$ is the silanol dissociation constant, and cation association:

$$
\begin{aligned}
\Gamma_{S_{i O C_{i}}} & =K_{C_{i}^{+}} \Gamma_{S_{i O}}\left[C_{i}^{+}\right]_{z=d} \\
& =K_{C_{i}^{+}} \Gamma_{S i O^{-}}\left[C_{i}^{+}\right] e^{-\frac{z_{i} e \phi\left(z_{\text {out }}\right)}{k_{B} T}}
\end{aligned}
$$

where $K_{C_{i}^{+}}$is the $C_{i}^{+}$surface association constant. The concentrations involving silanol groups $\Gamma_{\mathrm{SiOH}}, \Gamma_{\mathrm{SiO}^{-}}$and $\Gamma_{\mathrm{SiOC}_{i}}$ are surface concentrations and it has been made explicit that $H^{+}$ions are located at height 0 (surface) and $C_{i}^{+}$cations at height $\mathrm{z}_{\text {out }}$ (outer Helmholtz plane). $K_{H}$ and $K_{C_{i}^{+}}$are equilibrium constants. The total density of surface sites is

$$
\Gamma=\Gamma_{S i O^{-}}+\Gamma_{S i O H}+\sum_{i} \Gamma_{S_{i O C}}
$$

Combining Eqs(7)-(10), we get the adsorption isotherms:

$\Gamma_{S i O H}=\frac{\Gamma \frac{\left[H^{+}\right]}{K_{H}} e^{-\frac{e \phi(0)}{k_{B} T}}}{1+\frac{\left[H^{+}\right]}{K_{H}} e^{-\frac{e \phi(0)}{k_{B} T}}+\sum_{i} K_{C_{i}}\left[C_{i}^{+}\right] e^{-\frac{z_{i} e \phi\left(z_{\text {out }}\right)}{k_{B} T}}}$,

$\Gamma_{S i O C_{i}}=\frac{\Gamma K_{C_{i}}\left[C_{i}^{+}\right] e^{-\frac{z_{i} e \phi\left(z_{\text {out }}\right)}{k_{B} T}}}{1+\frac{\left[H^{+}\right]}{K_{H}} e^{-\frac{e \phi(0)}{k_{B} T}}+\sum_{i} K_{C_{i}}\left[C_{i}^{+}\right] e^{-\frac{z_{i} e \phi\left(z_{\text {out }}\right)}{k_{B} T}}}$,

and,

$\Gamma_{S i O^{-}}=\frac{\Gamma}{1+\frac{\left[H^{+}\right]}{K_{H}} e^{-\frac{e \phi(0)}{k_{B} T}}+\sum_{i} K_{C_{i}}\left[C_{i}^{+}\right] e^{-\frac{z_{i} e \phi\left(z_{\text {out }}\right)}{k_{B} T}}}$,

where $\phi(0)$ and $\phi\left(z_{\text {out }}\right)$ are still unknown. The potential dependence in the Stern layer can be obtained by considering the Stern layer as a molecular condenser where the potential drop is linear as there are no charge inside the Stern layer. Strictly speaking, when specific adsorption is taken into account, we should have a composite Stern layer, with protons adsorbed at $\mathrm{z}=0$ and cations at $\mathrm{z}_{\text {in }}$ (inner Helmholtz plane), the closest distance of approach of nonspecifically adsorbed ions being at the outer Helmholtz plane $z_{\text {out }}$. This is known as the triple layer model. ${ }^{4}$ We then have:

$$
\begin{aligned}
\phi(0)-\phi\left(z_{\text {out }}\right) & =\phi(0)-\phi\left(z_{\text {in }}\right)+\phi\left(z_{\text {in }}\right) \\
& -\phi\left(z_{\text {out }}\right) \\
& =\frac{-e\left(\Gamma_{S i O^{-}}-\Gamma_{S i O H}\right)}{C_{\text {Stern }}^{1}} \\
& -\frac{\sigma_{D L}}{C_{\text {Stern }}^{2}}
\end{aligned}
$$

where $-e\left(\Gamma_{\mathrm{SiO}^{-}}-\Gamma_{\mathrm{SiOH}}\right)$ is the effective surface charge on the first capacitor on the solid side with capacitance $C_{\text {Stern }}^{1}$ and $\sigma_{D L}$ is the surface charge on the second capacitor of capacitance $C_{\text {Stern }}^{2}{ }^{4}$ We use here a simplified model assuming that specific adsorption takes place at the outer Helmholtz plane $\mathrm{z}_{\text {out }}$. Then,

$$
\begin{aligned}
\phi(0)-\phi\left(z_{\text {out }}\right) & =-e \frac{\Gamma-\Gamma_{\text {SiOH }}}{C_{\text {Stern }}} \\
& =-\frac{e \sum_{i} z_{i} \Gamma_{S i O C}}{C_{\text {Stern }}} \\
& +\frac{\sigma_{D L}}{C_{\text {Stern }}},
\end{aligned}
$$

where $C_{\text {Stern }}$ is the effective capacitance of the Stern layer and charge balance has been taken into account:

$$
-e \Gamma+e \Gamma_{S i O H}+e \sum_{i} z_{i} \Gamma_{S i O C_{i}}+\sigma_{D L}=0 .
$$

The full set of 5 equations Eqs. (6),(11)(13),(15) are solved numerically to determine all surface and bulk concentrations as a function of the density of surface charges $\Gamma$, the concentrations of the different ions and $\mathrm{pH}$, and the Stern layer capacitance $C_{\text {Stern }}$. These equations will be used below to fit our experimental curves.

\section{Molecular dynamics}

Classical Molecular Dynamics (MD) simulations were performed to simulate the interfacial system. The model includes silica surfaces, water and ions. The silica surfaces have been 
generated with a Monte Carlo simulation, as detailed in Ref. ${ }^{53}$ We performed biased Potential of Mean Force (PMF) simulations and nonbiased simulations. The concept of PMF was introduced by Kirkwood. ${ }^{54}$ It is based on a statistical analysis : the probability of a given distance between two particles is linked to the free energy of the system. The gradient of the $\mathrm{PMF}$ is the average force experienced by the particle at a given distance. ${ }^{54}$ The difference in PMF between the values at infinite separation and at adsorption distance is the free adsorption energy. A computational difficulty is that distances with high potentials are not sampled efficiently. The Umbrella Sampling (US) ${ }^{55}$ is a computational method which uses biased potentials so as to sample all distances, including points with high potential. The PMF profile is initially produced in a series of profiles, each one spanning a small distance, which are assembled to make a global free energy profile. ${ }^{56,57}$

The simulations are performed in periodic othorhombic boxes, one for the PMF and one for the unbiased simulations. The surface area is $2.852 * 2.852=8.1339 \mathrm{~nm}^{2}$. Its height is 5 nm. It includes 29 silanol, which results in a density of 3.6 per $\mathrm{nm}^{2}$. This value is standard for silica. ${ }^{18}$ The surface includes a single deprotonated silanol, which results in a point charge on the surface.

Surface atoms do not move during simulation. The fluid temperature is kept constant at 300 K using a Nose-Hoover thermostat. ${ }^{58}$ The water is simulated with the rigid $\mathrm{SPC} / \mathrm{E}^{59}$ using the SHAKE algorithm. ${ }^{60}$ Ion potentials are due to Dang. ${ }^{61}$ All other interaction potentials are described with full details in, ${ }^{40}$ with two differences. The so-called "nm" potentials are fitted on a Lennard-Jones potential. The effective charges of atoms upon deprotonation are -e on deprotonated silanols and +1.5 e on the underlying silica atom, as detailed in. ${ }^{53}$

\section{Results}

\section{Model free analysis}

As the interpretation of standing wave curves is not intuitive, we start with a model free analysis which allows one to directly draw important conclusions from a direct analysis of the results.

Fluorescence is displayed as a function of the grazing angle of incidence across the Bragg peak on Fig.(5) for $10^{-3} \mathrm{M} \mathrm{K}^{+}$cations in a $100 \mathrm{~nm}$ thick film for different locations of the Helmholtz plane relative to the upper Silicon layer of a multilayer composed of $1502.58 \mathrm{~nm}$ Si-W periods like used in this study. The calculation was performed for $8 \mathrm{SiO}^{-}$sites per $\mathrm{nm}^{2}$, a Stern layer capacitance $C_{S}=2.9 F . \mathrm{m}^{-2}$ and a silanol dissociation constant $K_{H}=10^{-7.5} .^{5}$ Simulations for cation association constants equal to 10 and 100 are presented in Figs. 5 (a) and (b) respectively. In this simple calculation, all cations in the Stern layer sit at the same position, and the distribution in the diffuse layer is calculated accordingly. Qualitatively similar results would be obtained for a more complex distribution within the Stern layer with the same average position.

As can be seen on Fig. 5, when $\mathrm{z}_{\text {out }}$ increases from $\mathrm{z}_{\text {out }}=4$ to $\mathrm{z}_{\text {out }}=24$ (due for example to a thicker $\mathrm{SiO}_{2}$ layer), the center of the curve of the fluorescence curves shifts from right to left whereas the maximum of the curve to the baseline increases, passes through a maximum at $\mathrm{z}_{\mathrm{out}}=12$ and then decreases again. This means that the closest distance of approach of the different ions can be inferred from both the relative position of the center of the curve of the fluorescence curves and the ratio of their maximum above the baseline. Neglecting surface effects or for a very thick sample, fluorescence is centered at the Bragg peak location (2.073 degrees) with a maximum of fluorescence to baseline ratio of 1.58 . The center of the curve ( $\mathrm{CoC})$ of each experimental curve was thus calculated after subtraction of a linear background as well as the ratio of the maximum of the curves to their baseline at the position of the center of the curve. Average values are given in table 1). According to Fig.5, a large shift of the center 
Table 1: Center of the curve ( $\mathrm{CoC}$ ) and ratio of the maximum of the curve to the baseline at the the center of the curve position for $\mathrm{K}^{+}, \mathrm{Cs}^{+}$and $\mathrm{I}^{-}$.

\begin{tabular}{cccc} 
& $\mathrm{K}^{+}$ & $\mathrm{Cs}^{+}$ & $\mathrm{I}^{-}$ \\
\hline CoC & $2.070 \pm 0.003$ & $2.078 \pm 0.002$ & $2.075 \pm 0.003$ \\
ratio & $1.68 \pm 0.1$ & $1.46 \pm 0.05$ & $1.58 \pm 0.04$ \\
\hline
\end{tabular}

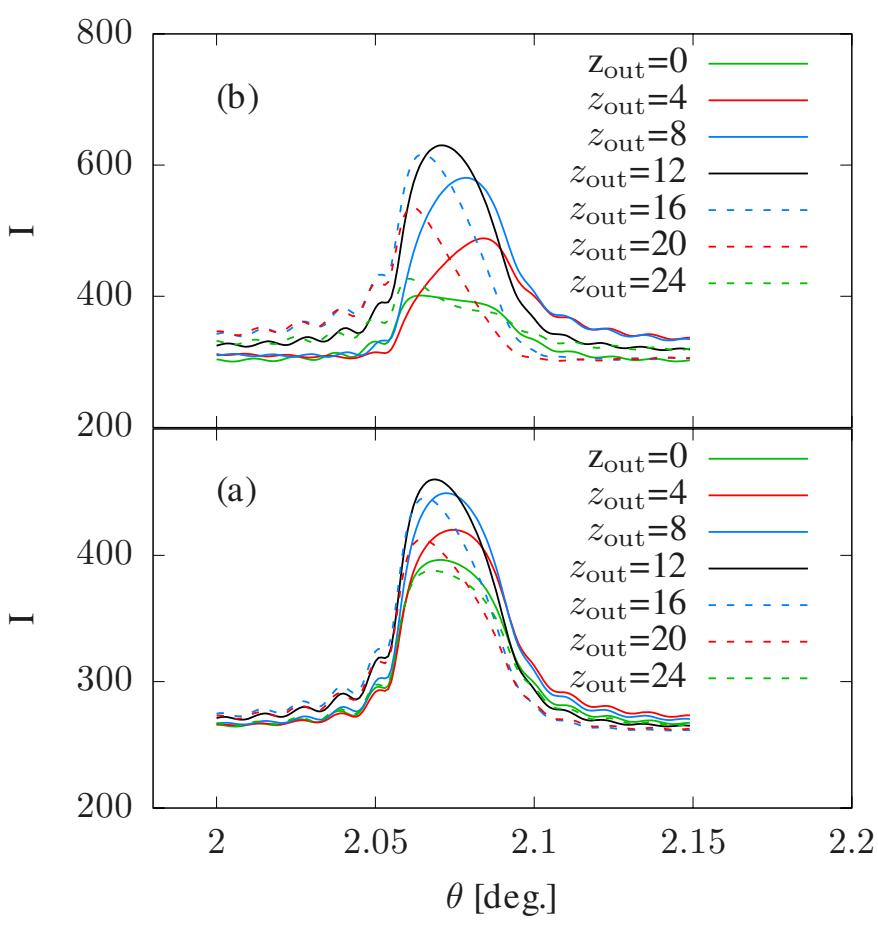

Figure 5: Calculated fluorescence vs grazing angle of incidence across the Bragg peak for $10^{-3}$ $\mathrm{M}$ cations in a $100 \mathrm{~nm}$ thick film with different locations $\mathrm{z}_{\mathrm{out}}$ of the Helmholtz plane relative to the upper Silicon layer of a multilayer composed of $1502.58 \mathrm{~nm} \mathrm{Si-W} \mathrm{periods} \mathrm{like} \mathrm{used} \mathrm{in}$ this study. The calculation was performed for $8 \mathrm{SiO}^{-}$sites per $\mathrm{nm}^{2}$, a Stern layer capacitance $C_{S}=2.9 F \cdot m^{-2}$, a silanol dissociation constant $K_{H}=10^{-7.5}$ and cation associations constants equal to 10 (a) and 100 (b). of the curve combined with a smaller ratio of maximum to baseline indicates a higher shift of the ion away from the surface. For $\mathrm{K}^{+}$and $\mathrm{Cs}^{+}$ions, we find $\mathrm{CoC}\left(K^{+}\right)=2.070 \pm 0.003$, $\operatorname{ratio}\left(K^{+}\right)=1.68 \pm 0.1, \mathrm{CoC}\left(C s^{+}\right)=2.078 \pm$ 0.002 and $\operatorname{ratio}\left(C s^{+}\right)=1.46 \pm 0.05$, showing that the maximum of the $\mathrm{K}^{+}$fluorescence is shifted to the left and is higher than the $\mathrm{Cs}^{+}$ fluorescence maximum, demonstrating that $\mathrm{K}^{+}$ lies closer to the surface than $\mathrm{Cs}^{+}$.

For $\mathrm{I}^{-}$ions, we have $\mathrm{CoC}\left(I^{-}\right)=2.075 \pm 0.003$, $\operatorname{ratio}\left(I^{-}\right)=1.58 \pm 0.04$. This is quite remarquable as these values are those obtained in absence of surface interactions. This means that, as expected, no specific interaction of $\mathrm{I}^{-}$ions with our silica surface is detectable. It can however not be fully ruled out at this stage that the $\mathrm{I}^{-}$ions always sit precisely in between $\mathrm{K}^{+}$and $\mathrm{Cs}^{+}$.

\section{Full analysis using the Gouy- Chapman-Stern model}

Based on this first analysis, we analyzed our data in a more quantitative way within the framework of the Gouy-Chapman-Stern model presented in Sect. "Analysis of the standing wave curves". Distribution profiles were first constructed for all ions in an experiment by solving Eqs. (6),(12),(13),(16) with different densities of surface sites, different values of the Stern layer, $\mathrm{pK}_{H}^{+}=7.5$ and different values of $K_{K^{+}}$and $K_{C^{+}}$, also leaving the position of the Helmholtz plane free for each ion. This last parameter has to be fitted as the thickness of the upper silicon layer could slightly vary from place to place and will in any case depend on its degree of oxydation. Steps of $10^{0.25}=1.77$ were used for the equilibrium constants and $2 \AA$ for the Helmholtz plane location. For each set of parameters, the distribution profiles were used 
to generate standing wave curves which were fitted to the experimental data by minimizing a global $\chi^{2}$ for all fluorescence curves belonging to the same experiment. All combinations of equilibrium constants in between 1 and 1000, and all possible locations of the Helmholtz planes in a standing wave period were systematically explored. Compared to our previous preliminary analysis, ${ }^{47}$ the present method has the advantage that all electrostatic constraints are automatically included, increasing the robustness of the analysis.

Representative results are displayed on Fig. 6, with the profile corresponding to Fig. 6a being represented on Fig. 7 and results are summarized in table 2.

First of all, good fits could be obtained for all curves, and equilibrium constants could be determined. A quite remarkable result is that, though fully unconstrained, we find consistent results for the Helmholtz plane location for the different cations in a same experiment. This is a strong demonstration of the consistency of the analysis. Note also that attempts to fit the experimental curves with only one Helmoltz plane location for all ions gave signifiantly higher $\chi^{2}$ values. Most of the $\mathrm{z}_{\text {out }}$ values are in between $20 \AA$ and $22 \AA$ which also shows that the upper oxidized silicon layer is slightly thicker than inner layers in the multilayer, as can be expected from the incorporation of oxygen atoms in the structure and verified by $x$-ray reflectivity. $\mathrm{z}_{\text {out }}^{C l}$ is sometimes shifted compared to cations which is clearly linked to the poor statistics we have for chlorine and also to the very smooth distribution for anions close to the surface. Remarkably, no fit gave a shorter distance of approach for $\mathrm{Cs}^{+}$cations compared to $\mathrm{K}^{+}$cations and the average difference between them is $1.75 \pm 1.0 \AA$. Turning now to association constants for the oxidized silica surface, we find both $\log \mathrm{K}_{K^{+}}=1.2 \pm 0.4$ and $\log \mathrm{K}_{\mathrm{Cs}^{+}}$ $=0.8 \pm 0.4$, i.e. a slightly more pronounced adsorption of $\mathrm{K}^{+}$compared to $\mathrm{Cs}^{+}$. We then explored the sensitivity of this result to the different parameters in the model.

If we take the number of sites per $\mathrm{nm}^{2}$ to be $5^{18}$ instead of 8 , we find, $\log K_{K^{+}}=1.5 \pm 0.4$ and

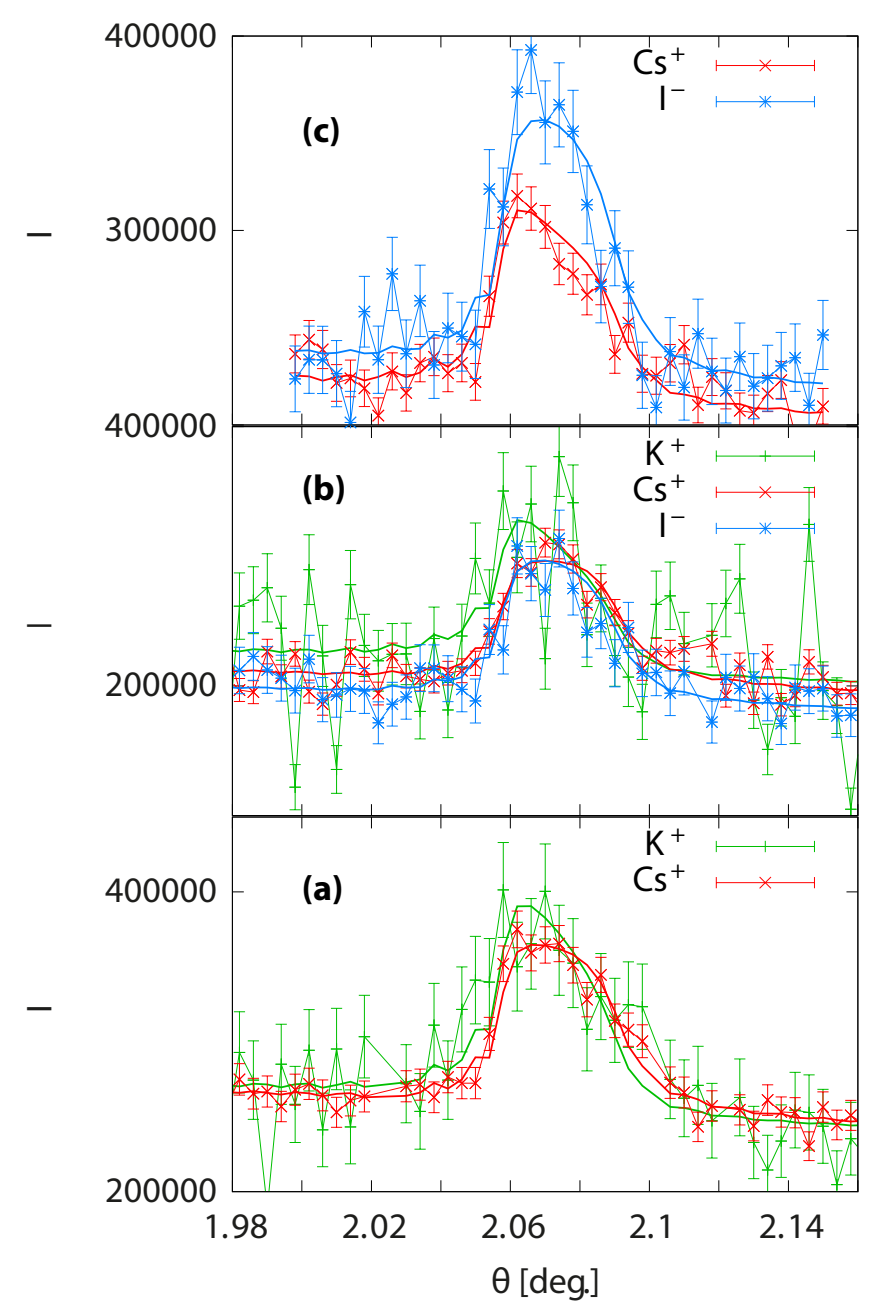

Figure 6: Representative fluorescence standing wave curves for different solutions. (a) mixture of $\mathrm{KCl} 10^{-3} \mathrm{M}$ and $\mathrm{CsCl} 10^{-3} \mathrm{M}, K_{K^{+}}=10^{1.5}$, $K_{C s^{+}}=10^{1.5}, \mathrm{z}_{\text {out }}^{K}=22, \mathrm{z}_{\text {out }}^{C s}=24$. (b) mixture of KI $10^{-3} \mathrm{M}$ and CsI $10^{-3} \mathrm{M}, K_{K^{+}}=10^{1.5}$, $K_{C s^{+}}=10^{1.0}, \mathrm{z}_{\text {out }}^{K}=22, \mathrm{z}_{\text {out }}^{C s}=24$. (c) mixture of $\mathrm{KCl} 10^{-3} \mathrm{M}$ and $\mathrm{CsI} 10^{-3} \mathrm{M}$ on silane, $K_{K^{+}}=10^{1.5}, K_{C s^{+}}=10^{1.5}, \mathrm{z}_{\text {out }}^{K}=22, \mathrm{z}_{\text {out }}^{C s}=$ 24 . 
$\log \mathrm{K}_{C s^{+}}=1.2 \pm 0.4$, i.e. a small increase in the association constants. As one could expect that the results could depend on the Stern layer capacitance, we also tested different values $\mathrm{C}_{S}$ $=0.5 \mathrm{~F} . \mathrm{m}^{-2}$ and $\mathrm{C}_{S}=6 \mathrm{~F} . \mathrm{m}^{-2}$. Best fits are obtained for the nominal $\mathrm{C}_{S}=2.9 \mathrm{~F} . \mathrm{m}^{-2}$, but the increase in $\chi^{2}$ is not significant for all the tested capacitance values. $\log \mathrm{K}$ values increase with decreasing capacitance, reaching $\log \mathrm{K}_{K^{+}}$ $=1.8 \pm 0.2$ and $\log \mathrm{K}_{C^{+}}=1.7 \pm 0.3$ for $\mathrm{C}_{S}$ $=0.5 \mathrm{~F} . \mathrm{m}^{-2}$. The difference is less for larger capacitances, with $\log K_{K^{+}}=0.9 \pm 0.4$ and $\log \mathrm{K}_{C s^{+}}=0.7 \pm 0.4$ for $\mathrm{C}_{S}=6.0 \mathrm{~F} . \mathrm{m}^{-2}$. This is correlated to the drop in surface potential across the Stern layer. We find silica surface potentials $\phi(0) \approx-110 \mathrm{mV}$ and a drop of $\approx$ 10 to $15 \mathrm{mV}$ across the Stern layer for $\mathrm{C}_{S}=$ $2.9 \mathrm{~F} . \mathrm{m}^{-2}$, slightly less for $\mathrm{C}_{S}=1 \mathrm{~F} . \mathrm{m}^{-2}$, but on the order of $50-80 \mathrm{mV}$ for $\mathrm{C}_{S}=0.5 \mathrm{~F} . \mathrm{m}^{-2}$. With a larger potential drop across the Stern layer, the contribution of the diffuse layer to the surface charge $\sigma_{D L}$ is lower, and is compensated by a higher specific adsorption as the experimental curves are mainly sensitive to the total amount of adsorbed cations.

In summary, the association constants are relatively insensitive to the model parameters, except for large values of the Stern layer capacitance.

The surface concentration of specifically adsorbed cations $\mathrm{K}^{+}$and $\mathrm{Cs}^{+}$is consistently on the order of $0.07 \mathrm{~nm}^{-2}$ for $10^{-3} \mathrm{M}$ solutions and $0.05 \mathrm{~nm}^{-2}$ for the $2 \times 10^{-3} \mathrm{M}$ solution, reminding that there are 8 adsorption sites per $\mathrm{nm}^{2}$, i.e. less than $1 \%$ of the sites are occupied by $\mathrm{K}^{+}$or $\mathrm{Cs}^{+}$cations at $\mathrm{mM}$ concentrations.

Weak specific adsorption was obtained at $\mathrm{pH}=2$, where surface potential and surface charge are weak. The experiments conducted on silanized surfaces gave contradictory results, one of them giving results similar to those for bare silica surfaces, and the other one a slightly stronger specific adsorption $\log \mathrm{K}_{K^{+}}=\log \mathrm{K}_{C^{+}}$ $=1.5$ possibly due to a different silane coverage. The surface charge is weak on the order of $0.05 \mathrm{C} / \mathrm{m}^{2}$ and is negligible at $\mathrm{pH}=2$.

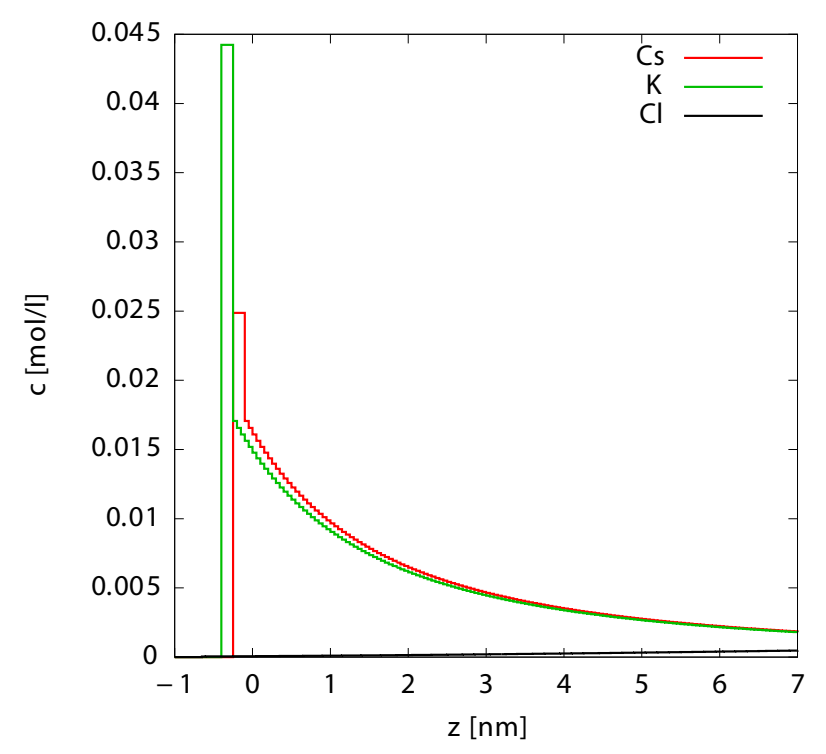

Figure 7: Distribution of $\mathrm{K}^{+}, \mathrm{Cs}^{+}$and $\mathrm{Cl}^{-}$for the best fit represented of Fig. $6 . K_{K^{+}}=10^{1.5}$, $K_{C s^{+}}=10^{1.5}, \mathrm{z}_{\text {out }}^{K}=22, \mathrm{z}_{\text {out }}^{C s}=24$.

\section{Numerical simulation}

As mentioned before, the full analysis of the fluorescence signal using the Gouy-ChapmanStern model indicates a shift between potassium and cesium positions. When both ions are in solution, potassium comes closer to the surface, with a shift of $0.2 \mathrm{~nm}$. This shift is too large to be accounted for by a difference in ionic radius, so the assumption is required that, in contrast to $\mathrm{K}^{+}, \mathrm{Cs}^{+}$does not share its hydration shell with surface (manuscript in preparation). We performed an Umbrella Sampling simulation on a surface deprotonated silanol with both cesium and potassium ions. The PMF profiles are plotted on Fig 8. It should be noted that for statistical reasons, millimolar concentrations as used in our experiments cannot be simulated, preventing us from a direct comparison of experimental and simulated profiles.

As already evidenced, ${ }^{40}$ there is a clear tendency that when potassium and cesium are competing for surface adsorption on a negative silica surface, the former comes preferentially in contact with the charged surface atoms. The spreading of the punctual -e negative surface charge among the surrounding surface atom is a difficult issue ${ }^{62}$ and has a strong effect on ion- 
surface interaction. ${ }^{40}$ It appears that, with a variety of hypotheses on surface charges spreading, we steadily find a preferential selectivity for the smaller cations, as it is shown by our standing waves experiments.

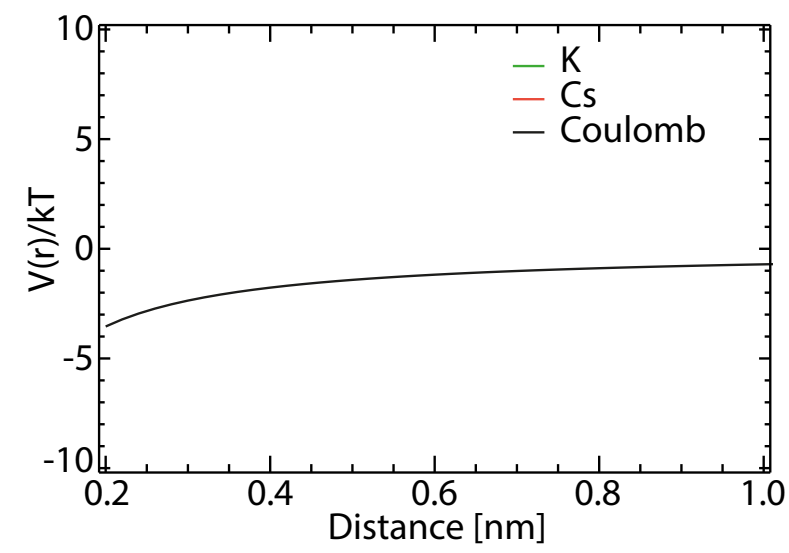

Figure 8: Potential of Mean Force for $\mathrm{K}^{+}$and $\mathrm{Cs}^{+}$calculed by molecular dynamics as detailed in Sect. "Molecular dynamics".

\section{Discussion}

The adsorption of monovalent cations on various silica surfaces has been investigated using different experimental methods over decades. Compared to previously used methods, the strength of our experimental method is to combine sensitivity to the chemical nature of the ions with $\AA$ resolution. Like in the surface force apparatus, large sufaces are also investigated, unlike in experimental methods using colloidal probes.

First of all, we note that our data could be analyzed with surface charges similar to those obtained in titration experiments, i.e. on the order of $0.05 \mathrm{C} / \mathrm{m}^{2}{ }^{5,14,31}$ Same applies for the surface potential on the order of $100 \mathrm{mV}$. Only Ref. ${ }^{31}$ gives much higher potentiels, but at $\mathrm{pH}$ $=10$.

Association constants determined using different methods are displayed in table 2 together with our data. Though all studies tend to agree on a value of $\mathrm{H}^{+}$dissociation constant with $\mathrm{pK}_{H^{+}}$in the range $6.2-7.5$, no agreement is found for the comparatively weaker associa- tion of monovalement cations, not even on their ranking with respect to adsorption strength. Force measurement methods apparently lead to larger values of the association constants giving $\log \mathrm{K}$ values on the order of 2 to 3 whereas titration methods give $\log \mathrm{K}$ values on the order of -0.5 to 1 . Reversal of the adorption strength with $\mathrm{pH}$ is sometimes found, but even there, there is no agreement regarding the order at low or high $\mathrm{pH}$.

We find slightly larger association constants for $\mathrm{K}^{+}$than for $\mathrm{Cs}^{+}$or the order of $\log \mathrm{K} \approx 1.0$ to 1.5. Both trends, i.e. stronger association of $\mathrm{K}^{+}$or $\mathrm{Cs}^{+}$, are found in the literature (see table 2), but the difference is always less or on the order of $0.5 \log$ units and depends on surface chemistry.

We also find that $\mathrm{K}^{+}$cations come closer to the surface than $\mathrm{Cs}^{+}$cations by $1.75 \pm 0.4 \AA$. This is in agreement with the potential of mean force displayed in Fig. 8 and with the simulations of Hocine et al. ${ }^{41}$ who argues that smaller cations better share their hydration shell with the surface, as also pointed out in Refs. ${ }^{28,43}$

\section{Conclusion}

$\mathrm{X}$-ray standing wave technique has been used in this study in order to investigate the electrical double layer of 0.1 - $1 \mathrm{mM}$ alkali-halide solutions at oxidized silicon surfaces. Compared to a previous investigation, data were analyzed using the Gouy-Chapman-Stern model, allowing for a direct determination of association constants.

These experiments demonstrate that $\mathrm{x}$-ray standing waves under well defined experimental conditions can bring most valuable information about the structure of the electrical double layer.

In this study, large samples $(1 \mathrm{~cm} \times 1 \mathrm{~cm})$ were used. With the smallest beam size presently available at synchrotrons $(50 \mathrm{~nm})$, the beam footprint would be less than $2 \mu \mathrm{m}$ for a similar grazing of incidence of 2 degrees opening the possibility to study much smaller samples. Another limitation of the method is that the contribution of the interfacial profile has to be 
large enough compared to that of the rest of the liquid film implying that the investigation of higher concentrations would require thinner cells. We are presently developing cells with a thickness on the order of $10 \mathrm{~nm}$ which will allow the investigation of $0.1 \mathrm{M}$ solutions.

Using highly precise measurements to test hypotheses on surface ion interaction potentials is a key development is establishing a set of reliable potentials for numerical simulations. More experimental systems are currently under investigation and will be published soon.

\section{Acknowledgements}

The ITN network SOMATAI (FP7 people: Marie-Curie Actions. Grant number 316866 ) is gratefully acknowledged for funding the PhD grant of Soumaya ben Jabrallah and synchrotron SOLEIL for beamtime. This work was granted access to the HPC resources of [TGCC/CINES/IDRIS] under the allocation 2019-A0070910963 made by GENCI (Grand Equipement National de Calcul Intensif). The authors gratefully thank A. Hemmerle for a critical reading of the manuscript and the code used to analyze the data. This work is dedicated to Prof. Peter S. Pershan (Harvard University), a founding father of the field of x-ray studies of liquid surfaces, on his $85^{\text {th }}$ birthday. 
Table 2: Comparison of $\mathbf{p K} \mathrm{H}^{+}, \log \left(\mathrm{K}_{\mathrm{Li}^{+}}\right), \log \left(\mathrm{K}_{\mathrm{Na}^{+}}\right) \log \left(\mathrm{K}_{\mathrm{K}^{+}}\right)$and $\log \left(\mathrm{K}_{\mathrm{Cs}^{+}}\right)$obtained using different methods. (a) 4nm pyrogenic AEROSIL 300 silica nanoparticles, concentrations in between $0.005{\mathrm{~m} .1^{-1}}$ and $0.3 \mathrm{~m} .1^{-1}$. (b) Data from Ref. ${ }^{21}$ were used in Ref. ${ }^{13}$ (c) Silica powder, concentrations $0.01 \mathrm{~m} .1^{-1}, 0.1 \mathrm{~m} .1^{-1}$ and $1.0 \mathrm{~m} .1^{-1}$, double extrapolation method. (d) Surface force apparatus, pyrogenic silica surfaces in $10^{-4} \mathrm{M}-10^{-1} \mathrm{M}$ electrolytes at pH $=5.5$. (e) AFM, force measured between the tip and a silica surface in $1 \mathrm{mM}-100 \mathrm{mM}$ solutions. (f) MUSIC model. (g) Use of different thermodynamic and structural data. (h) Potential of mean force calculation using molecular dynamics. (i) Fixed value in the fit.

\begin{tabular}{|c|c|c|c|c|c|c|c|}
\hline & $\begin{array}{l}\text { Number of } \\
\text { sites }\left(\mathrm{nm}^{-2}\right)\end{array}$ & $\begin{array}{c}\mathrm{C}_{S} \\
\left(\mathrm{~F} \cdot \mathrm{m}^{-2}\right)\end{array}$ & $\mathrm{pK}_{H^{+}}$ & $\log \left(\mathrm{K}_{L i^{+}}\right)$ & $\log \left(\mathrm{K}_{N a^{+}}\right)$ & $\log \left(\mathrm{K}_{K^{+}}\right)$ & $\log \left(\mathrm{K}_{C s^{+}}\right)$ \\
\hline \multicolumn{8}{|l|}{ Titration of silica particles } \\
\hline Sonnefeld ${ }^{a 15}$ & 0.62 & & 6.24 & $\leq-6$ & -1.32 & -0.48 & 0.23 \\
\hline Davis et al. ${ }^{b 13}$ & 5. & 1.25 & 7.2 & & & 0.5 & \\
\hline Tao and Hongxia ${ }^{c 22}$ & & & 6.57 & $1.0 \pm 0.1$ & $1.0 \pm 0.1$ & $1.0 \pm 0.1$ & \\
\hline \multicolumn{8}{|l|}{ Force measurements } \\
\hline Chapel $^{d 26}$ & 2. & & $6.2-6.5$ & 3.46 & 3.25 & 3.2 & 2.97 \\
\hline Zhao et al..$^{29}$ & 8. & 2.9 & $6.9 \pm 0.3$ & & $1.65 \pm 0.1$ & $2.0 \pm 0.2$ & \\
\hline \multicolumn{8}{|l|}{ Theory and simulations } \\
\hline Hiemstra et al. $f 34$ & & & 7.5 & & & & \\
\hline Sverjensky $^{g 37}$ & & $0.9-1.2$ & $6.2-7.0$ & 0.8 & 0.9 & 1.3 & 2.0 \\
\hline $\begin{array}{l}\text { Hocine et al. }{ }^{h} \text { (basic conditions, } \\
-1.5 \text { e charge on } \mathrm{SiOH})^{41}\end{array}$ & & & & 9.12 & 3.4 & 0.35 & -0.17 \\
\hline \multicolumn{8}{|l|}{ This work } \\
\hline & $8 .^{i}$ & $2.9^{i}$ & $6.9^{i}$ & & & $1.2 \pm 0.4$ & $0.8 \pm 0.4$ \\
\hline & $5 .^{i}$ & $2.9^{i}$ & $6.9^{i}$ & & & $1.5 \pm 0.4$ & $1.2 \pm 0.2$ \\
\hline & $8 .^{i}$ & $0.5^{i}$ & $6.9^{i}$ & & & $1.8 \pm 0.2$ & $1.7 \pm 0.3$ \\
\hline & $8 .^{i}$ & $6.0^{i}$ & $6.9^{i}$ & & & $0.9 \pm 0.4$ & $0.7 \pm 0.4$ \\
\hline
\end{tabular}




\section{References}

(1) Larcher, D.; Tarascon, J.-M. Towards Greener and more Sustainable Batteries for Electrical Energy Storage. Nat. Chem. 2015, 7, 19-29.

(2) Koopal, L.; Saito, T.; Pinheiroa, J.; van Riemsdijk, W. Ion Binding to Natural Organic Matter: General Considerations and the NICA-Donnan Model. Colloids Surf., A 2005, 265, 40-54.

(3) Foster, K.; Plastridge, R.; Bottenheim, J.; Shepson, P.; Finlayson-Pitts, B.; W., S. C. The Role of $\mathrm{Br}_{2}$ and $\mathrm{BrCl}$ in Surface Ozone Destruction at Polar Sunrise. Science 2001, 291, 471-474.

(4) Lyklema, J. Fundamentals of Interface and Colloid Science: Solid-Liquid Interfaces; Academic Press, 1995.

(5) Trefalt, G.; Behrens, S.; Borkovec, M. Charge Regulation in the Electrical Double Layer: Ion Adsorption and Surface Interactions. Langmuir 2015, 32, 380-400.

(6) Collins, K.; Washabaugh, M. The Hofmeister Effect and the Behaviour of Water at Interfaces. Quart. Rev. Biophys. 1985, 18, 323-422.

(7) Cacace, M.; Landau, E.; Ramsden, J. The Hofmeister. series: salt and solvent effects on interfacial phenomena. Quart. Rev. Biophys. 1997, 30, 241-277.

(8) Kunz Ed., W. Specific Ion effects; World Scientific: Singapore, 2009.

(9) Collins, K.; Neilson, G.; Enderby, J. Ions in Water: Characterizing the Forces that Control Chemical Processes and Biological Structure. Biophys. Chem. 2007, 128, 95-104.

(10) Jungwirth, P.; Tobias, D. Specific Ion Effects at the Air/Water Interface. Chem. Rev. 2006, 106, 1259-1281.
(11) Koelsch, P.; Viswanath, P.; Motschmann, H.; Shapovalov, V. L.; Brezesinski, G.; Mohwald, H.; Horinek, D.; Netz, R. R.; Giewekemeyer, K.; Alditt, T. S. et al. Specific Ion Effects in Physicochemical and Biological Systems: Simulations, Theory and Experiments. Colloids Surf., A 2007, 303, 110-136.

(12) Lyklema, J.; Tadros, T. Adsorption of Potential-Determining Ions at the SilicaAqueous Electrolyte Interface and the Role of some Cations. J. Electroanal. Chem. 1968, 17, 267-275.

(13) Davis, J.; James, R.; Leckie, J. Surface Ionization and Complexation at the Oxide/Water Interface I. Computation of Electrical Double Layer Properties in Simple Electrolytes. J. Colloid Interface Sci. 1978, 63, 480-499.

(14) Sonnefeld, J.; Göbel, A.; Vogelsberger, W. Surface Charge Density on Spherical Silica Particles in Aqueous Alkali Chloride Solutions Part 1. Experimental Results. Colloid and Polym. Sci. 1995, 273, 926-931.

(15) Sonnefeld, J. Surface Charge Density on Spherical Silica Particles in Aqueous Alkali Chloride Solutions Part 2. Evaluation of the Surface Charge Density Constants. Colloid Polym. Sci. 1995, 273, 932-938.

(16) Borkovec, M.; Jönsson, B.; Koper, G. Ionization Processes and Proton Binding in Polyprotic Systems: Small Molecules, Proteins, Inteifaces, and Polyelectrolytes, E. Matijevic Ed. Surface and Colloid Science 2001, 16, 99-339.

(17) Ti Tien, H. Interaction of Alkali Metal Cations with Silica Gel. J. Phys. Chem. 1965, 69, 350-352.

(18) Zhuravlev, L. Concentration of Hydroxyl Groups on the Surface of Amorphous Silicas. Langmuir 1987, 3, 316-318. 
(19) Hiemstra, T.; van Riemsdijk, W.; Bolt, G. Multisite Proton Adsorption Modeling at the Solid/Solution Interface of (Hydr)oxides: A New Approach. $J$. Colloid Interface Sci. 1989, 133, 91-104.

(20) Kobayashi, M.; Skarba, M.; Galletto, P.; Cakara, D.; Borkovec, M. Effects of Heat Treatment on the Aggregation and Charging of Stöber-Type Silica. J. Colloid Interface Sci. 2005, 292, 139-147.

(21) Abendroth, R. Behavior of a Pyrogenic Silica in Simple Electrolytes. J. Colloid Interface Sci. 1970, 34, 591.

(22) Tao, Z.; Zhang, H. Acidity and Alkali Metal Adsorption on the SiO2 - Aqueous Solution Interface. J. Colloid Interface Sci. 2002, 252, 15-20.

(23) Ermakova, I.; Sidorova, M.; Bogdanova, M. Influence of the Structure of Boundary Layers and the Nature of Counterions on the Position of the Isoelectric Point of Silica Surfaces. Colloid Journal 2006, 68, 411-416.

(24) Pashley, R. DLVO and Hydration Forces between Mica Surfaces in $\mathrm{Li}^{+}, \mathrm{Na}^{+}, \mathrm{K}^{+}$, and $\mathrm{Cs}^{+}$Electrolyte Solutions: A Correlation of Double-Layer and Hydration Forces with Surface Cation Exchange Properties. J. Colloid Interface Sci. 1981, 83, 531-546.

(25) Miklavic, S.; Ninham, B. Competition for Adsorption Sites by Hydrated Ions. J. Colloid Interface Sci. 1990, 134, 305-311.

(26) Chapel, J.-P. Electrolyte Species Dependent Hydration Forces between Silica Surfaces. Langmuir 1994, 10, i4237-4243.

(27) Dishon, M.; Zohar, .; Sivan, U. From Repulsion to Attraction and Back to Repulsion: The Effect of $\mathrm{NaCl}, \mathrm{KCl}$, and $\mathrm{CsCl}$ on the Force between Silica Surfaces in Aqueous Solution. Langmuir 2009, 25, 2831-2836.
(28) Morag, J.; Dishon, M.; Sivan, U. The Governing Role of Surface Hydration in Ion Specific Adsorption to Silica: An AFMBased Account of the Hofmeister Universality and Its Reversal. Langmuir 2013, 29, 6317-6322.

(29) Zhao, C.; Ebeling, D.; Siretanu, I.; van der Ende, D.; Mugele, F. Extracting Local Surface Charges and Charge Regulation Behavior from Atomic Force Microscopy Measurements at Heterogeneous SolidElectrolyte Interfaces. Nanoscale 2015, 7, 16298-16311.

(30) Cheng, M.; Callahan, K.; Margarella, A.; Tobias, D.; Hemminger, J.; Bluhm, H.; Krisch, M. Ambient Pressure X-ray Photoelectron Spectroscopy and Molecular Dynamics Simulation Studies of Liquid/Vapor Interfaces of Aqueous $\mathrm{NaCl}$, $\mathrm{RbCl}$, and $\mathrm{RbBr}$ Solutions. J. Phys. Chem. C 2012, 116, 4545-4555.

(31) Brown, M.; Abbas, Z.; Kleibert, A.; Green, R.; Goel, A.; May, S.; Squires, T. Determination of Surface Potential and Electrical Double-Layer Structure at the Aqueous Electrolyte-Nanoparticle Interface. Phys. Rev. X 2016, 6, 011007.

(32) Brown, M.; Goel, A.; Abbas, Z. Effect of Electrolyte Concentration on the Stern Layer Thickness at a Charged Interface. Angew. Chem. Int. Ed 2016, 55, 37903794.

(33) Gmür, T.; Goel, A.; Brown, M. Quantifying Specific Ion Effects on the Surface Potential and Charge Density at Silica Nanoparticle-Aqueous Electrolyte Interfaces. J. Phys. Chem. C 2016, 120, 16617-16625.

(34) Hiemstra, T.; van Riemsdijk, W.; Bolt, G. Multisite Proton Adsorption Modeling at the Solid/Solution Interface of (Hydr)oxides: A New Approach. II. Application to Various Important (Hydr)oxides. J. Colloid Interface Sci. 1989, $133,105117$. 
(35) Bolt, G. Determination of the Charge Density of Silica Sols. J. Phys. Chem. 1957, 61, 1166-1169.

(36) Hiemstra, T.; van Riemsdijk, W. A Surface Structural Approach to Ion Adsorption: The Charge Distribution (CD) Model. J. Colloid Interface Sci. 1996, 179, 488-508.

(37) Sverjensky, D. Prediction of Surface Charge on Oxides in Salt Solutions: Revisions for 1:1 $\mathrm{M}^{+} \mathrm{L}^{-}$Electrolytes. Geochim. et Cosmochim. Acta 2005, 69, 225-257.

(38) Schwierz, N.; Horinek, D.; Netz, R. Reversed Anionic Hofmeister Series: The Interplay of Surface Charge and Surface Polarity. Langmuir 2010, 26, 7370-7379.

(39) Schwierz, N.; Horinek, D.; Netz, R. Anionic and Cationic Hofmeister Effects on Hydrophobic and Hydrophilic Surfaces. Langmuir 2013, 29, 2602-2614.

(40) Hocine, S.; Hartkamp, R.; Siboulet, B.; Duvail, M.; Coasne, B.; Turq, P.; Dufreche, J.-F. How Ion Condensation Occurs at a Charged Surface: a Molecular Dynamics Investigation of the Stern Layer for Water Silica Interfaces. J. Phys. Chem. C 2016, 120, 963-973.

(41) Hocine, S. PhD thesis. University of Montpellier 2017,

(42) Bouhadja, M.; Skelton, A. Dynamical Properties of Water and Ions at the Quartz (101)-Water Interface at a Range of Solution Conditions: A Classical Molecular Dynamics Study. J. Phys. Chem. C 2018, 122, 1535-1546.

(43) Dewan, S.; Carnevale, V.; Bankura, A.; Eftekhari-Bafrooei, A.; Fiorin, G.; Klein, M.; Borguet, E. Structure of Water at Charged Interfaces: A Molecular Dynamics Study. Langmuir 2014, 30, 8056-8065.

(44) Zegenhagen, J., Ed. The X-Ray Standing Wave Technique: Principles and Applications; World Scientific Publishing, 2013.
(45) Bedzyk, M.; Bommarito, G.; Caffrey, M.; Penner, T. Diffuse-Double Layer at a Membrane-Aqueous Interface Measured with X-ray Standing Waves. Science 1990, 248, 52-56.

(46) Park, C.; Fenter, P.; Nagy, K.; Sturchio, N. Hydration and Distribution of Ions at the Mica-Water Interface. Phys. Rev. Lett. 2006, 97, 016101.

(47) ben Jabrallah, S.; Malloggi, F.; Beloni, L.; Girard, L.; Novikov, D.; Mocuta, C.; Thiaudière, D.; Daillant, J. Electrolytes at Interfaces: Accessing the First Nanometers Using X-Ray Standing Waves. Phys. Chem. Chem. Phys. 2017, 19, 167-174.

(48) Gibaud, A.; Vignaud, G. Specular Reflectivity from Smooth and Rough Surfaces. X-Ray and Neutron Reflectivity: Principles and Applications. Berlin Heidelberg, 2009; pp 87-139.

(49) Grundner, M.; Jacob, H. Investigations on Hydrophilic and Hydrophobic Silicon (100) Wafer Surfaces by X-Ray Photoelectron and High-Resolution Electron Energy Loss-Spectroscopy. Appl. Phys. A 1986, 39, 73-82.

(50) Kern, W. The Evolution of Silicon Wafer Cleaning Technology. J. Electrochem. Soc., 1990, 137, 1887-1892.

(51) Padmanabhan, V.; Daillant, J.; Belloni, L.; Mora, S.; Alba, M.; Konovalov, O. Specific Ion Adsorption and Short-Range Interactions at the Air Aqueous Solution Interface. Phys. Rev. Lett. 2007, 99.

(52) van Gysel, M.; Lemberge, P.; van Espen, P. Implementation of a Spectrum Fitting Procedure using a Robust Peak Model. X-ray Spectrometry 2003, 32, 434-441.

(53) Siboulet, B.; Hocine, S.; Hartkamp, R.; Dufreche, J.-F. Scrutinizing ElectroOsmosis and Surface Conductivity with Molecular Dynamics. J. Phys. Chem. C 2017, 121, 6756-6769. 
(54) Kirkwood, J. Statistical Mechanics of Fluid Mixtures. J. Chem. Phys. 1935, 3, 300-313.

(55) Torrie, G.; Vallleau, J. Non-Physical Sampling Distributions in Monte-Carlo FreeEnergy Estimation - Umbrella Sampling. J. Comput. Phys. 1977, 23, 187-199.

(56) Kumar, S.; Bouzida, D.; Swendsen, R.; Kollman, P.; Rosenberg, J. The Weighted Histogram Analysis Method for FreeEnergy Calculations on Biomolecules. 1. The Method. J. Comput. Chem. 1992, 13, 1011-1021.

(57) Roux, B. The Calculation of the Potential of Mean Force Using ComputerSimulations. Comput. Phys. Comm. 1995, 91, 275-282.

(58) Hoover, W. G. Canonical Dynamics: Equilibrium Phase-Space Distributions. Phys. Rev. A 1985, 31, 1695-1697.

(59) Berendsen, H.; Grigera, J.; Straatsma, T. The Missing Term in Effective Pair Potentials. J. Phys. Chem. 1987, 91, 62696271.

(60) Ryckaert, J.; Ciccotti, G.; Berendsen, H. Numerical-Integration of Cartesian Equations of Motion of a System with Constraints - Molecular Dynamics of nAlkanes. J. Comput. Phys. 1977, 23, 327341.

(61) Dang, L. Mechanism and Thermodynamics of Ion Selectivity in Aqueous-Solutions of 18-crown-6 ether - a Molecular Dynamics Study. J. Am. Chem. Soc. 1995, 117, 6954-6960.

(62) Cruz-Chu, E. R.; Aksimentiev, A.; Schulten, K. Water-Silica Force Field for Simulating Nanodevices. J. Phys. Chem. B 2006, 110, 21497-21508. 


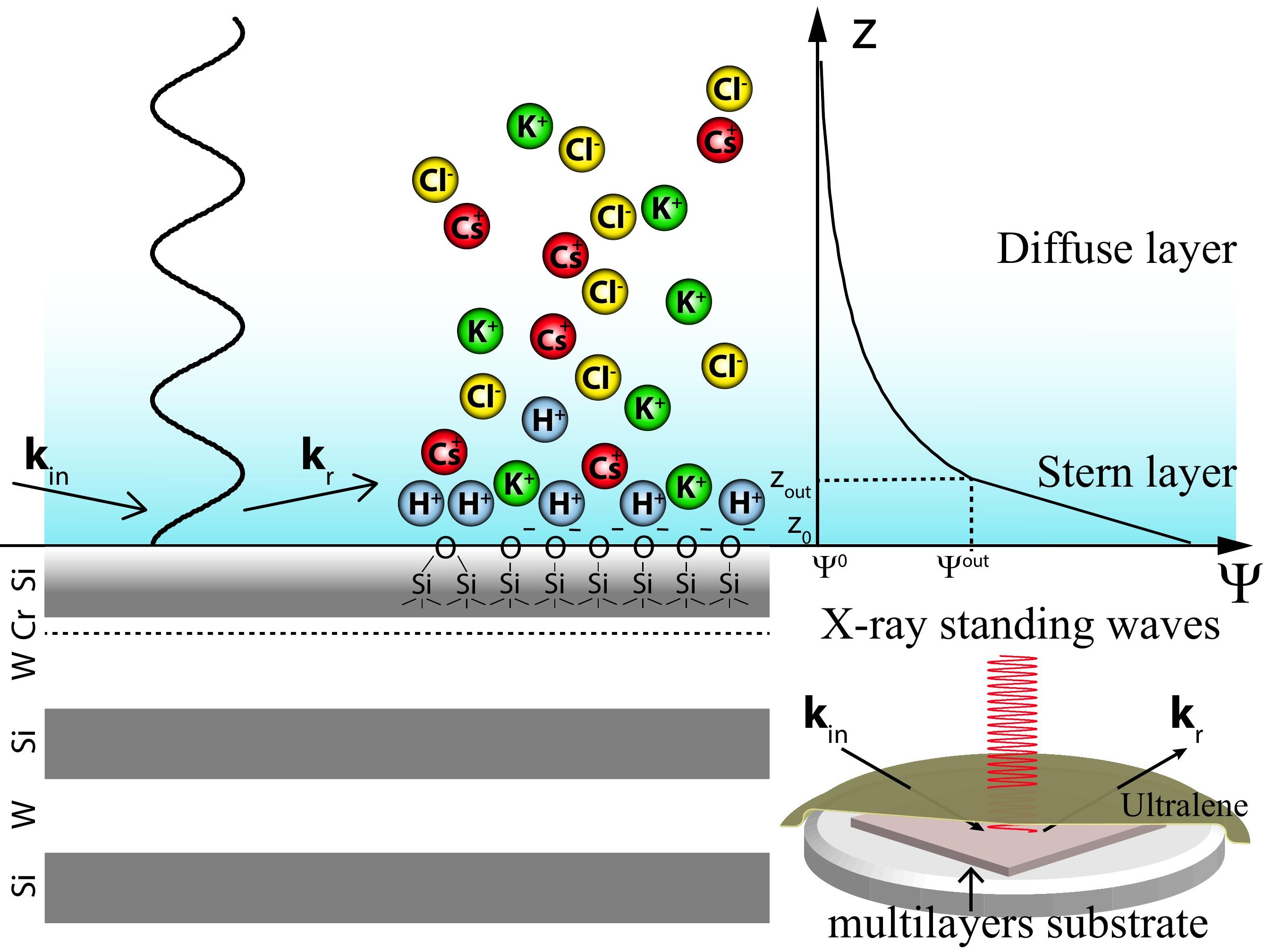




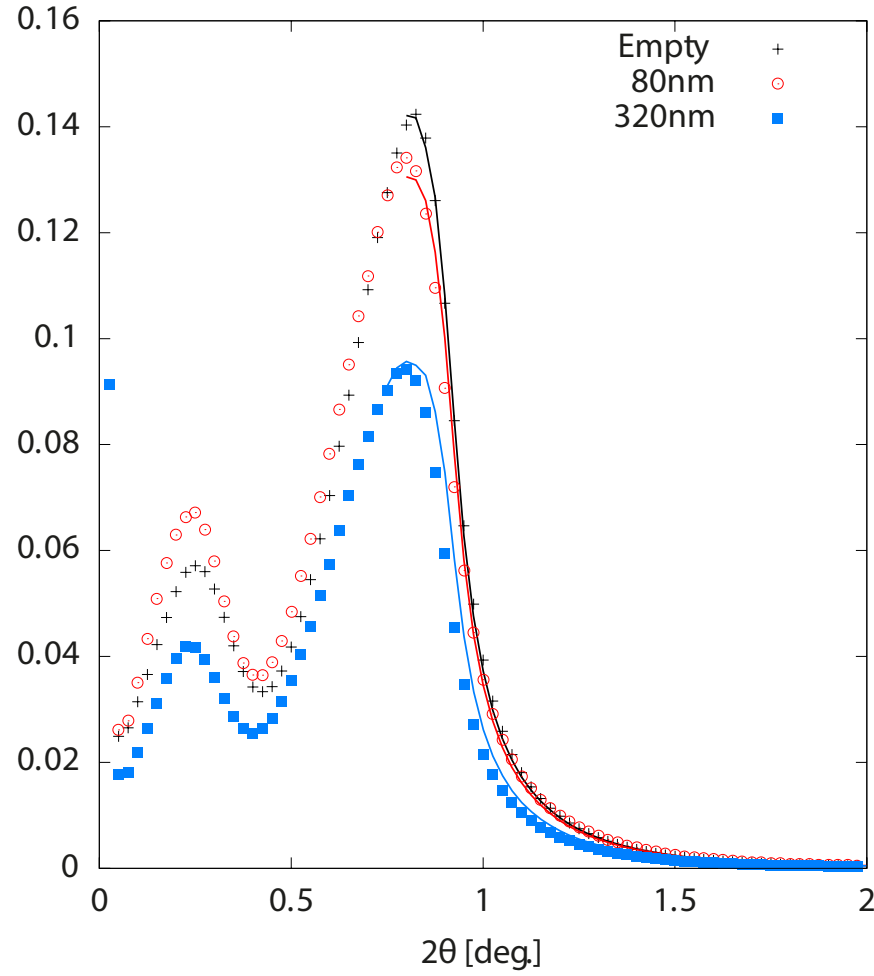




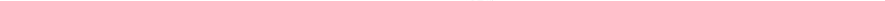




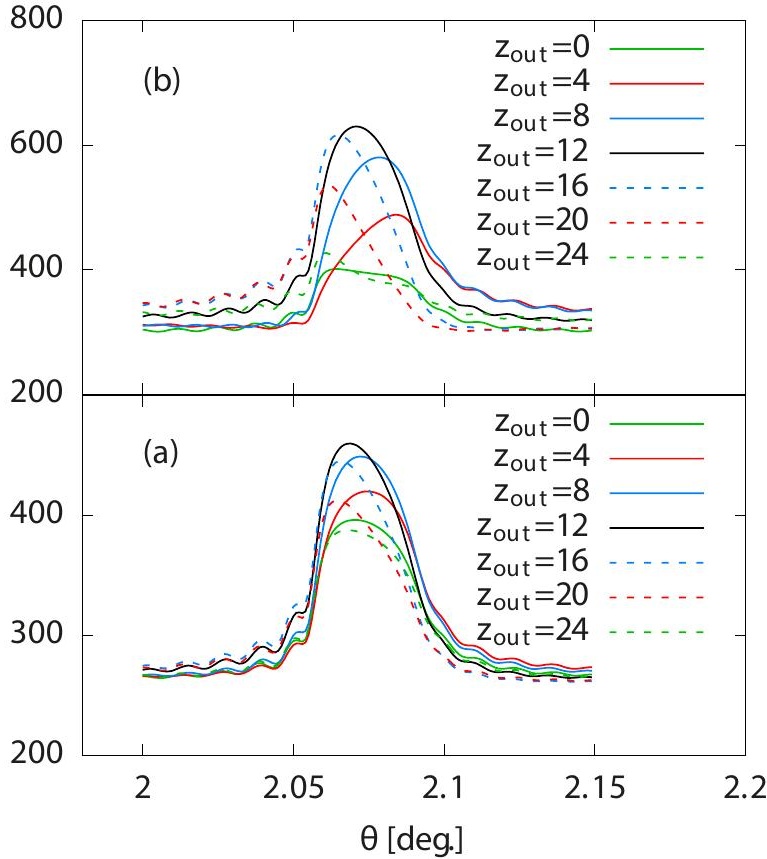




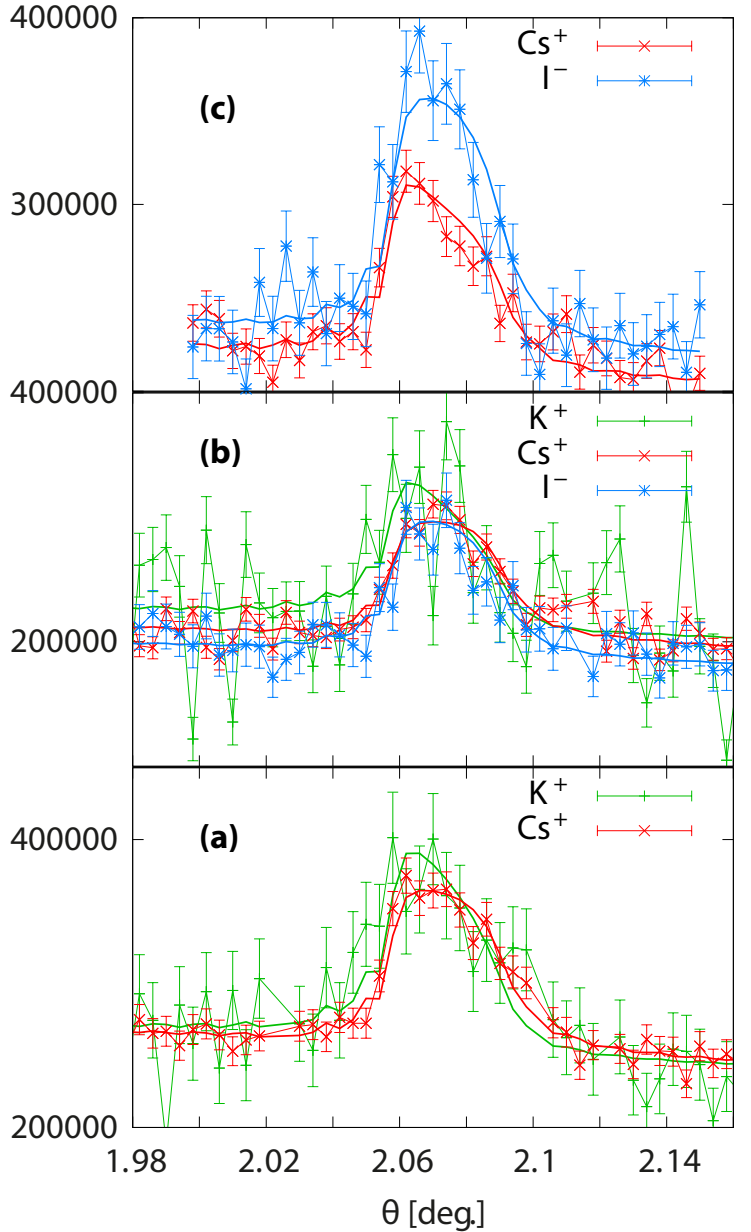




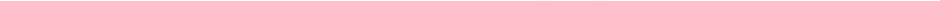




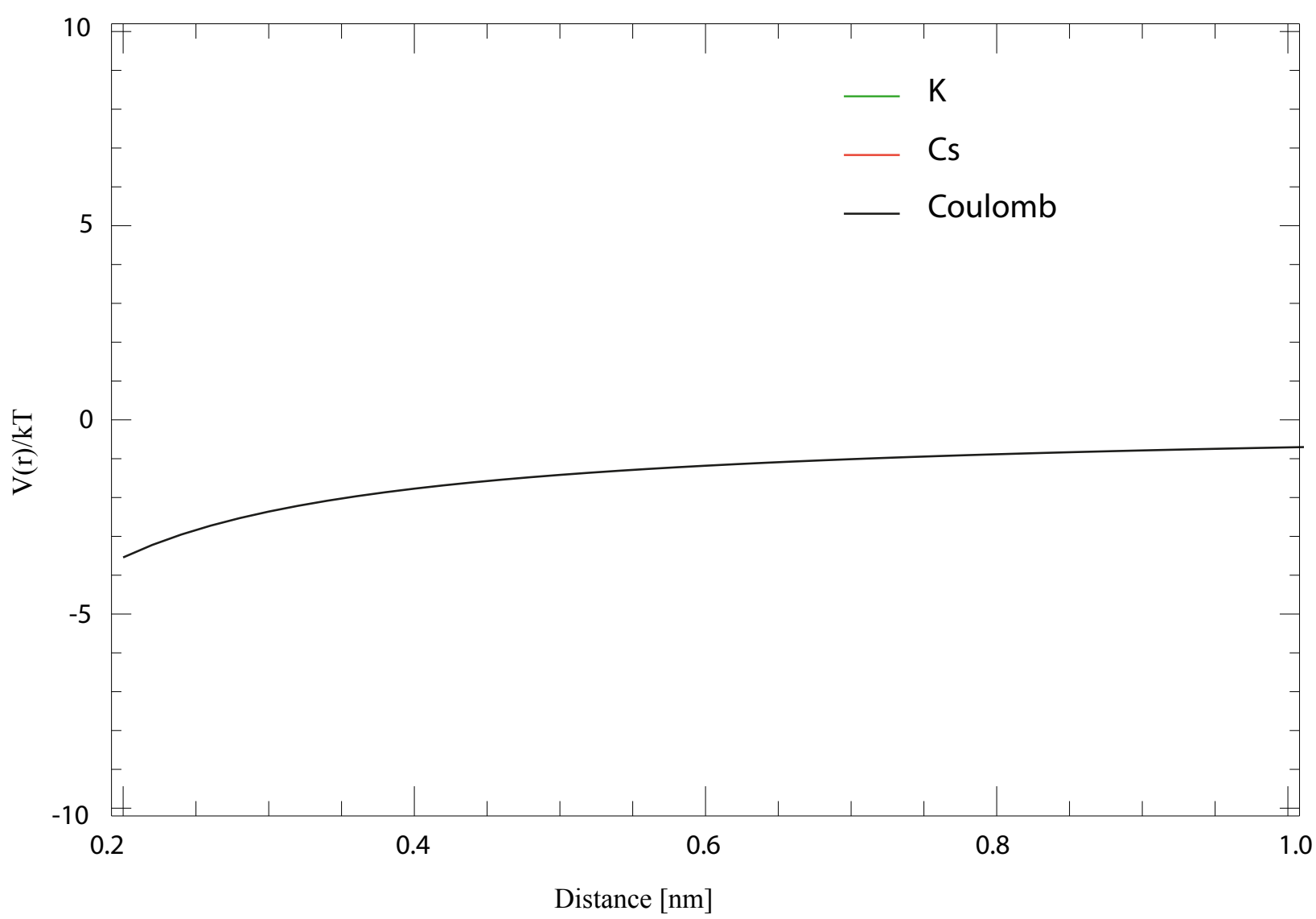


Energy [eV]

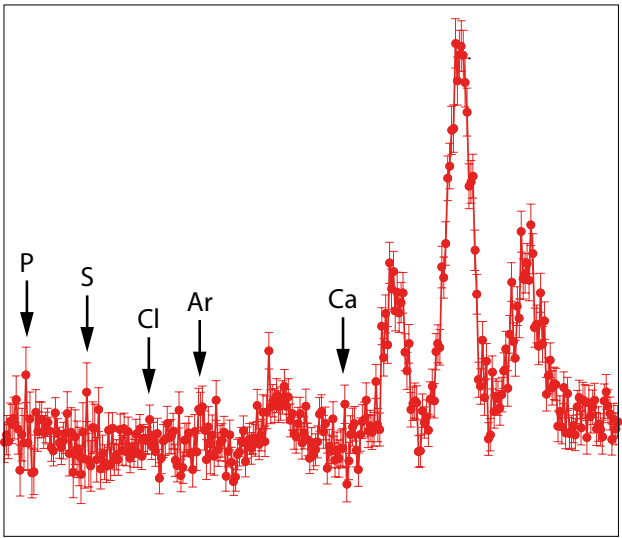

$\frac{2}{3}$

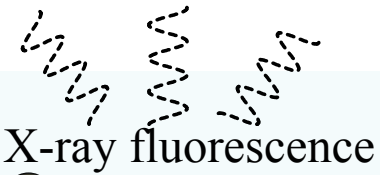

on

(C)

(C)

(C) $\mathrm{K}^{+}$

(C)

(C) $\mathrm{K}^{+}$

(K) Cs

(C) $\mathrm{H}^{+} \mathrm{KI}^{+}$

(C)

$x$

k

in
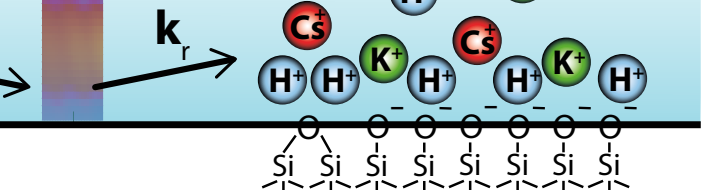